\title{
Natural Uranium Radioactivity Solution Standard: SRM 4321d
}

\author{
Ronald Collé, Lizbeth Laureano-Pérez, Svetlana Nour, Jerome J. La Rosa, Brian E. Zimmerman, \\ Leticia Pibida, and Denis E. Bergeron
}

National Institute of Standards and Technology, Gaithersburg, MD 20899-8462, USA

ronald.colle@nist.gov

lizbeth.laureano-perez@nist.gov

svetlana.nour@nist.gov

jerome.larosa@nist.gov

brian.zimmerman@nist.gov

leticia.pibida@nist.gov

denis.bergeron@nist.gov

\begin{abstract}
A new natural uranium solution standard has been produced and will be disseminated by the National Institute of Standards and Technology (NIST) as Standard Reference Material 4321d. The standard is certified for the massic activities of ${ }^{234} \mathrm{U},{ }^{235} \mathrm{U}$, and ${ }^{238} \mathrm{U}$ in solution, and it is based on isotopic mass data for the metallic Certified Reference Material (CRM) 112-A (originally issued as SRM 960) that was obtained from THE U.S. Department of Energy, New Brunswick Laboratory. The metallic CRM was chemically cleaned, dissolved, and gravimetrically diluted to prepare a master solution, which was quantitatively dispensed into $5 \mathrm{~mL}$ aliquots that were contained within flame-sealed glass ampoules for each SRM unit. Homogeneity among SRM units, verifying solution homogeneity, was substantiated by photonic-emission integral counting with a NaI(Tl) well counter. Confirmatory measurements were performed by liquid scintillation counting for the total massic activity, and by isotope dilution $\alpha$ spectrometry for the ${ }^{234} \mathrm{U}$ and ${ }^{238} \mathrm{U}$ massic activities.
\end{abstract}

Key words: isotope dilution analysis; liquid scintillation (LS); natural uranium; Standard Reference Material (SRM); uranium-234; uranium-235; uranium-238.

Accepted: October 30, 2017

Published: December 27, 2017

https://doi.org/10.6028/jres.122.044

\section{Introduction}

Natural uranium refers to the element of atomic number $Z=92$ (uranium) in the same isotopic ratios of ${ }^{234} \mathrm{U},{ }^{235} \mathrm{U}$, and ${ }^{238} \mathrm{U}$ as found in nature. All three isotopes are primordial radionuclides with half-lives ranging from $10^{5}$ years to $10^{9}$ years. There are three naturally occurring radioactive series, and two of these series, termed the "actinium series" and "uranium series," are headed by ${ }^{235} \mathrm{U}$ and ${ }^{238} \mathrm{U}$, respectively. The shorter-lived ${ }^{234} \mathrm{U}$ isotope is a decay product in the ${ }^{238} \mathrm{U}$ uranium series. Figure 1 shows the initial and relevant parts of these decay chains that lead to ${ }^{230} \mathrm{Th}$ and ${ }^{231} \mathrm{~Pa}$, with half-lives of $>10^{4}$ years. The isotopic ratios in natural uranium, in terms of radioactivity, correspond to approximately $49 \%{ }^{234} \mathrm{U}, 2 \%{ }^{235} \mathrm{U}$, and $49 \%{ }^{238} \mathrm{U}$. 


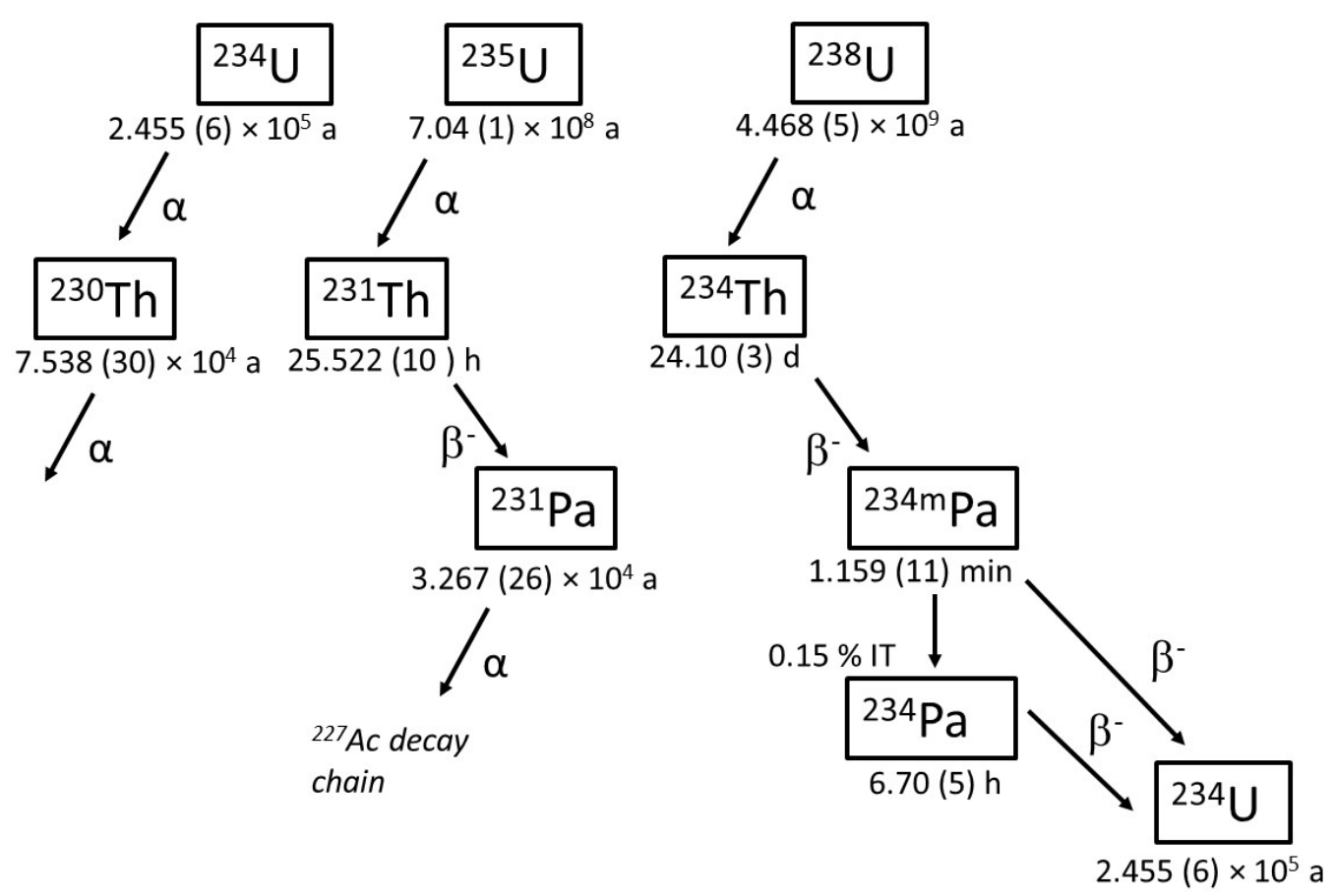

Fig. 1. Decay chain of the natural uranium isotopes ${ }^{234} U,{ }^{235} U$, and ${ }^{238} U$. The half-life for each nuclide was obtained from the Decay Data Evaluation Project (DDEP) [1].

A natural uranium radioactivity solution standard was last issued by the National Institute of Standards and Technology (NIST) nearly 20 years ago as a Standard Reference Material (SRM) ${ }^{1}$ and has been out of stock and unavailable for many years. Previous issues, all derived from the same stock uranium metal isotopic standard, were: SRM 4321 in 1986, SRM 4321b in 1992, and SRM 4321c in 1997 [2]. These standards are used for calibrating $\alpha$-particle counting instruments, for monitoring of radiochemical procedures, and for testing measurement proficiency by laboratories. They are needed by wide segments of the environmental measurement community and for geophysical research, particularly in examining uranium series disequilibrium and for ${ }^{230} \mathrm{Th} / \mathrm{U}$ dating methods. For example, SRM $4321 \mathrm{~b}$ was recently used to calibrate and make corrections for uranium-series isotope analysis by thermal-ionization mass spectrometry that was part of a study of a 130000 year old archaeological site in southern California, USA [3], showing evidence of human manipulation of broken stones and mastodon bone fractures. Even critics of the study's conclusions concur that the geochronology dating of the site was flawless [4]. If correct, the study indicates that some unknown species of Homo was in North America over 100000 years earlier than previously believed. This species would be ancestors of Neanderthals or members of some other extinct human lineage, unrelated to any living group of people. The dating of this remarkable archeological finding can in part be attributed to the availability of a natural uranium radioactivity solution standard.

This paper describes the production of a new issue of a natural uranium radioactivity solution standard by NIST, viz., SRM 4321d.

\footnotetext{
${ }^{1}$ A Standard Reference Material ${ }^{\circledR}$ (SRM), trademarked and disseminated by NIST, is a certified reference material that is issued with a certificate that provides the value of the specified property, its associated uncertainty, and a statement of metrological traceability.
} 


\section{Overview, Experimental Design, and Production}

\subsection{CRM 112-A Stock Material}

The standardization of SRM 4321d for the massic activities of ${ }^{234} \mathrm{U},{ }^{235} \mathrm{U}$, and ${ }^{238} \mathrm{U}$ is linked, both in terms of origin and certified values, to an isotopic mass standard, Certified Reference Material (CRM) 112A [5], which was obtained from the U.S. Department of Energy, New Brunswick Laboratory (NBL). This CRM consists of a natural uranium metal bar having an assay purity of (99.975 \pm 0.006$) \%$ by mass and a relative atomic mass of $238.028918 \pm 0.000$ 012, with certified values for atom percentages of ${ }^{234} \mathrm{U},{ }^{235} \mathrm{U}$, and ${ }^{238} \mathrm{U}$ isotopes (given in the second column of Table 1 ), ${ }^{2}$ as obtained from mass spectrometry. Each unit consists of a metal bar of nominal mass, ranging from $4 \mathrm{~g}$ to over $25 \mathrm{~g}$, as listed on the container. The CRM has a significant amount of surface oxide that requires chemical cleaning before use.

Table 1. Calculation of the activity per unit mass of the CRM 112-A metal for each uranium isotope, as obtained from the atom percentages given in the CRM 112-A Certificate of Analysis [5] and the DDEP-evaluated half-lives [1]. Numbers in parentheses represent the numerical value of the uncertainty and refer to the corresponding last digits of the quoted result. The atom percent uncertainty is two times the standard uncertainty, as given in the CRM Certificate, while those for the half-life and activity per unit mass are standard uncertainties.

\begin{tabular}{|c|c|c|c|}
\hline $\begin{array}{c}\text { Uranium } \\
\text { isotope }\end{array}$ & Atom percent of isotope (\%), $I$ & Half-life (a), $T$ & $\begin{array}{c}\text { Activity per unit mass of CRM 112-A } \\
\left(\mathrm{Bg} \mathrm{g}^{-1}\right), A\end{array}$ \\
\hline${ }^{234} \mathrm{U}$ & $0.0052458(81)$ & $2.455(6) \times 10^{5}$ & $1.1871(30) \times 10^{4}$ \\
\hline${ }^{235} \mathrm{U}$ & $0.72017(39)$ & $7.04(1) \times 10^{8}$ & $5.6834(82) \times 10^{2}$ \\
\hline${ }^{238} \mathrm{U}$ & $99.24748(39)$ & $4.468(5) \times 10^{9}$ & $1.2344(14) \times 10^{4}$ \\
\hline
\end{tabular}

The provenance of the CRM 112-A material is convoluted. The history is summarized in NIST and NBL certificates $[1,5]$. The material was produced by Mallinckrodt Chemical Works (St. Louis, MO, USA) using the direct-ingot or "dingot” technique, which produces high-purity massive uranium metal with low carbon content. The ingot was shipped to New Brunswick Laboratory in 1959 and was subsequently processed and cut into smaller bars at National Lead of Ohio (Fernald, OH, USA). Production details are available in a NBL report [8]. Measurements and certification of the uranium assay were performed at the National Bureau of Standards (NBS, now NIST), and the material was originally issued in 1972 by NBS as SRM 960 [9]. All technical and administrative aspects of the NBS special nuclear material SRMs, including SRM 960, were transferred to the NBL program in 1987. In 1998, NBL repackaged the material and verified the uranium assay and atomic mass. In 2010, NBL again repackaged the material and performed isotopic certification and assay verification measurements.

The relation between activity $A$ and number of atoms $N$ for a radionuclide is directly proportional, with the decay constant $\lambda$ as proportionality constant, leading to $A$ being inversely proportional to the radionuclide's half-life $T$, i.e., $A=N \lambda=N \frac{\ln 2}{T}$. With this, the activity per gram, $A_{i}$, in units of Bq $\mathrm{g}^{-1}$, for each of the three isotopes in CRM 112-A was calculated using

$$
A_{i}=\frac{P}{W} L I_{i} \frac{\ln 2}{T_{i}}
$$

where

$P$ is the fractional uranium assay (purity) certified for CRM 112-A (given above);

$W$ is the relative atomic mass for CRM 112-A (given above);

$L$ is the Avogadro constant taken to be $6.022140857(74) \times 10^{23} \mathrm{~mol}^{-1}$;

$I_{i}$ is the isotopic atom ratio for the isotope in CRM 112-A (Table 1, col. 2); and

\footnotetext{
${ }^{2}$ The stated uncertainties are two times the standard uncertainty. Unless otherwise noted, all uncertainties given in the paper correspond to standard uncertainties multiplied by a coverage factor of $k=2$. Certain nuclear data (e.g., half-lives) and fundamental physical constants (e.g., Avogadro number) are given, by convention, only as standard uncertainties. At times, uncertainties may be given as numbers in parentheses, which represent the numerical value of the uncertainty and refer to the corresponding last digits of the quoted result. The treatment and reporting of uncertainties follows NIST policy and international conventions given in Taylor and Kuyatt [6] and JCGM [7].
} 
$T_{\mathrm{i}}$ is the half-life of the isotope (Table1, col. 3) in seconds using a conversion of $31556926 \mathrm{~s} \mathrm{a}^{-1}$ for the mean solar year.

The results for the calculated individual isotopic activities per gram of CRM 112-A metal from Eq. (1) are given in Table 1. These values served as the basis for linking a measured mass of the CRM to the massic activities for the SRM 4321d solution standard.

The overall scheme to produce SRM 4321d is illustrated in Fig. 2. As indicated, the CRM metal was first chemically cleaned, rinsed, and dried, and its mass was determined by two independent gravimetric measurements. Second, the metal was dissolved in nitric acid and subsequently diluted to form a largevolume master solution, after an acidity adjustment. The master solution was dispensed in $5 \mathrm{~mL}$ aliquots into borosilicate glass ampoules, which were then flame-sealed.

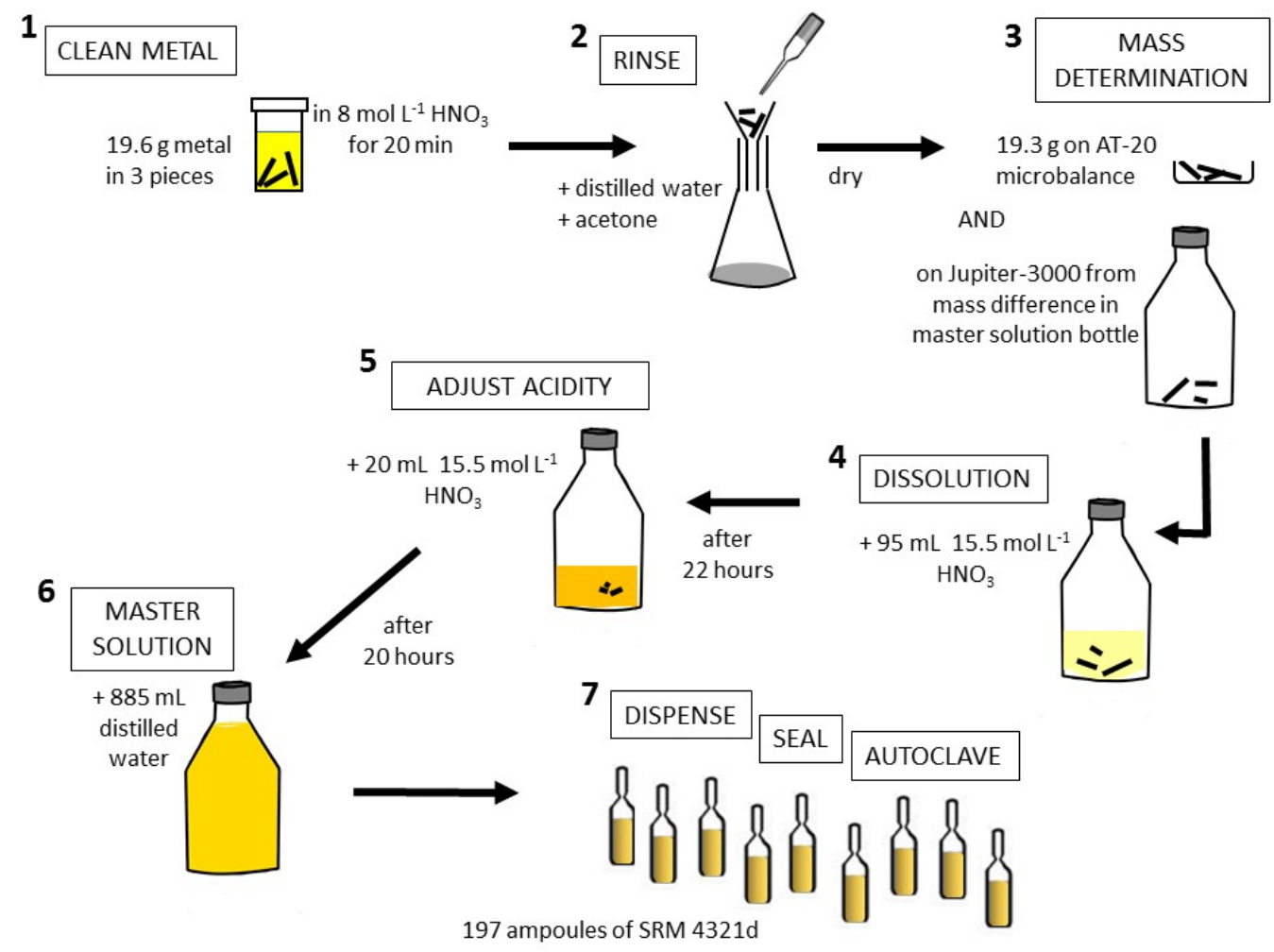

Fig. 2. General scheme used for the production of SRM 4321d. Refer to text for details.

\subsection{Chemical Cleaning and Gravimetry of Metal}

Before initiating the gravimetry and dissolution of CRM 112-A, the metal bar required cleaning. The material was acquired in 1997, and the $26 \mathrm{~g}$ bar had been cut into smaller sections for more convenient handling. Three pieces in the range of $5 \mathrm{~g}$ to $7 \mathrm{~g}$ were used for this work. As recommended by NBS for the original SRM 960 [9], the chemical cleaning procedure used to remove the $\mathrm{UO}_{2}$ surface contamination from the metallic bar consisted of the following steps:

a) metal was immersed in $8 \mathrm{~mol} \mathrm{~L}^{-1} \mathrm{HNO}_{3}$ for 20 min, which removed all visible black, dusty surface oxides;

b) cleaned metal was rinsed with deionized, distilled water to remove residual $\mathrm{HNO}_{3}$;

c) metal was rinsed with pure acetone to wash off residual water;

d) acetone was evaporated for $90 \mathrm{~s}$; and 
e) on immediately weighing the metal, readings were observed as a function of time until constant mass was reached.

Mass differences from weighing the metal before and after cleaning indicated that approximately 300 $\mathrm{mg}$ of mass were removed in the cleaning (about $1.6 \%$ of the initial mass).

Figure 3 displays the results of the gravimetric determinations of the mass of CRM 112-A used for the dissolution and for the total solution mass. The mass of the cleaned metal was determined first by quickly weighing the metal in a weighing boat with a Mettler AT20 electronic microbalance (Mettler-Toledo, Columbus, OH., USA). ${ }^{3}$ The mass was also determined with a large-capacity ( $3 \mathrm{~kg}$ ) mechanical balance with optical scale (Voland Jupiter 3000) ${ }^{4}$ from the mass difference of a $1 \mathrm{~L}$ master solution reagent bottle before and after the metal was added to the bottle. The relative difference in the two mass determinations was $0.04 \%$.

\section{Mass of U metal}

$\begin{array}{lll}\text { AT-20 } & \mathbf{1 9 . 3 1 8 0 4 5 \mathrm { g }} \quad \Delta=0.042 \% \\ \text { Jupiter } & 19.31159 \mathrm{~g}\end{array}$

\section{Mass master solution}

\begin{tabular}{|c|c|c|}
\hline standard weights & observed mass $\left(t s_{\mathrm{m}}\right)$ & $\%$ difference \\
\hline $\begin{array}{c}\left(607.8+\sum \delta\right) \mathrm{g} \\
?\end{array}$ & $\begin{array}{l}607.80089(25) \mathrm{g} \\
607.83444(32) \mathrm{g}\end{array}$ & $+1.5 \times 10^{-4} \%$ \\
\hline$(607.9+\Sigma \delta) g$ & $607.90158(87) \mathrm{g}$ & $+2.6 \times 10^{-4} \%$ \\
\hline $\begin{array}{c}\left(1648.4+\sum \delta\right) g \\
\text { 凡 }\end{array}$ & $\begin{array}{l}1648.39948(94) \mathrm{g} \\
1648.49083(147)\end{array}$ & $-3.2 \times 10^{-5} \%$ \\
\hline$(1648.5+\Sigma \delta) g$ & $1648.49997(50) \mathrm{g}$ & $-1.8 \times 10^{-6} \%$ \\
\hline \multicolumn{3}{|c|}{ buoyancy correction } \\
\hline $\begin{array}{l}\text { d weight } \\
\text { corrections }\end{array}$ & x 1.000974836 & $41.67 \mathrm{~g}$ \\
\hline
\end{tabular}

Fig. 3. Gravimetric determinations of the mass of the CRM 112-A cleaned uranium metal used for the dissolution and the total solution mass. The mass of the U metal was obtained by two independent determinations using the AT-20 microbalance and the largecapacity Jupiter balance. The two results given, with a relative difference of $0.042 \%$, include air buoyancy corrections. The total mass of the master solution was obtained from the mass difference readings between the empty and filled bottle. This difference was multiplied by the air buoyancy correction shown. The balance was checked with added standardized weights (with the sum of the weight corrections $\delta$ for the added weights) at values bracketing each of the two readings. The numbers in parentheses represent the replication precision of the observed mass readings, given as $t s_{\mathrm{m}}$ (product of Student's $t$ value for $n=3$ with $p=0.95$ and the standard deviation of the mean), and refer to the corresponding last digits of the quoted result.

\footnotetext{
${ }^{3}$ Certain commercial equipment, instruments, or materials are identified in this paper to foster understanding. Such identification does not imply recommendation or endorsement by the National Institute of Standards and Technology, nor does it imply that the materials or equipment identified are necessarily the best available for the purpose.

${ }^{4}$ Voland \& Sons, Inc., formerly of New Rochelle, NY, USA.
} 


\subsection{Dissolution and Solution Gravimetry}

Prior to the initiation of this work, there was an element of uncertainty in the dissolution of uranium with nitric acid. Given that the final master solution was intended to have an acid amount-of-substance concentration (molarity) of about $1 \mathrm{~mol} \mathrm{~L}^{-1}$, it was important to know the required $\mathrm{HNO}_{3}: \mathrm{U}$ amount-ofsubstance (mole) ratio needed to dissolve the metal. This would determine the amount of $\mathrm{HNO}_{3}$ to be used for the dissolution. The stoichiometry was conflicting. None of the major references on uranium chemistry [10-12] addressed the issue. A paper by Larsen [13] reported that the dissolution reaction with nitric acid is "complicated, with the acid reduction products varying from nitrogen dioxide to ammonia." In generalizing, Larsen concluded that at acidities of less than $8 \mathrm{~mol} \mathrm{~L}^{-1}$, nitrous oxide was the principal gaseous product, while at higher acidities, nitrogen dioxide is the principal product. Balanced chemical reactions or amount-of-substance (mole) ratios were not given. Conflicting NIST laboratory records and anecdotal information [14] suggested that the dissolution of uranium with concentrated nitric acid had an $\mathrm{HNO}_{3}: \mathrm{U}$ amount-of-substance ratio in the range of 3 to 4 with the evolution of $\mathrm{H}_{2}$. It subsequently became apparent that this was in error. Yet, based on the report by Larsen [13], the balanced reactions yielding either $\mathrm{NO}$ or $\mathrm{NO}_{2}$ were derived to be: and

$$
\mathrm{U}+4 \mathrm{HNO}_{3} \rightarrow \mathrm{UO}_{2}\left(\mathrm{NO}_{3}\right)_{2}+2 \mathrm{H}_{2} \mathrm{O}+2 \mathrm{NO}
$$

$\mathrm{U}+8 \mathrm{HNO}_{3} \rightarrow \mathrm{UO}_{2}\left(\mathrm{NO}_{3}\right)_{2}+4 \mathrm{H}_{2} \mathrm{O}+6 \mathrm{NO}_{2}$, indicating that the dissolution either required a $4: 1$ or $8: 1$ amount-of-substance ratio for $\mathrm{HNO}_{3}: \mathrm{U}$. A conservative 4:1 choice was initially chosen for the amount of concentrated $\mathrm{HNO}_{3}$ to add, knowing that an acidity adjustment could be subsequently made if necessary.

Dissolution of the nominal $19.3 \mathrm{~g}$ of the cleaned metal was made with $95 \mathrm{~mL}$ of $15.5 \mathrm{~mol} \mathrm{~L}^{-1} \mathrm{HNO}_{3}$. It was soon readily apparent that the 8:1 amount-of-substance ratio was operative, given that huge volumes of the characteristic reddish-brown $\mathrm{NO}_{2}$ were observed. To ensure that the final master solution had a desired $1 \mathrm{~mol} \mathrm{~L}^{-1} \mathrm{HNO}_{3}$ amount-of-substance concentration, an additional $20 \mathrm{~mL}$ of $15.5 \mathrm{~mol} \mathrm{~L}^{-1} \mathrm{HNO}_{3}$ was added after $22 \mathrm{~h}$ of dissolution. Minute particulate matter was observed in the master solution bottle, so the dissolution in the concentrated solution was allowed to continue for another $20 \mathrm{~h}$ until there was no further evidence of any remaining particulate matter. After expelling all excess $\mathrm{NO}_{2}$, the resulting solution was diluted with a nominal $885 \mathrm{~mL}$ of distilled water to form the SRM 4321d master solution. Figure 3 shows the careful gravimetric determination of the total master solution mass on the Jupiter-3000 balance. The mass of the empty bottle at about $607.8 \mathrm{~g}$ and the mass of the filled bottle at about $1648.4 \mathrm{~g}$ were closely bracketed by balance checks with OIML Class E1 standard weights. ${ }^{5}$ The relative differences between the standard weights and mass measurements for these balance checks were in the range of $10^{-4} \%$ to $10^{-6} \%$ in all cases.

\subsection{Ampoule Preparation}

The resulting SRM 4321d master solution was dispensed into 197 borosilicate glass ampoules using a Microlab 620 single-syringe automatic dispenser (Hamilton Company, Reno, NV, USA). The deeply yellow-colored uranyl nitrate solution consisted of $21 \mathrm{mg} \mathrm{UO}_{2}{ }^{+2}$ per gram of solution in (1.06 \pm 0.01$)$ mol $\mathrm{L}^{-1} \mathrm{HNO}_{3}$ with a density of $(1.057 \pm 0.001) \mathrm{g} \mathrm{mL}^{-1}$ at $21.6^{\circ} \mathrm{C}$. Fourteen ampoules, roughly every fifteenth one that was filled, were weighed before and after they were filled to obtain an estimate of the dispensing precision and contained solution mass. Weighing was performed with an electronic analytical balance (Mettler AE240). The average mass was $5.2843 \mathrm{~g}$, with a relative standard deviation of $0.11 \%$ for the $n=$ 14 sample distribution. Figure 4 shows the relative invariance in the solution mass with the ampoule filling order. After filling and weighing, the ampoules were (1) flame-sealed with a natural gas $/ \mathrm{O}_{2}$ torch on the Collé-Cavallo NIST-custom sealer, (2) inspected for flaws, (3) autoclaved in a pressure vessel for $20 \mathrm{~min}$ at $0.10 \mathrm{MPa}(\approx 15 \mathrm{psi})$ and about $120^{\circ} \mathrm{C}$, and (4) labelled.

\footnotetext{
${ }^{5}$ Organisation Internationale de Métrologie (OIML), which defines the requirements for various classes of weights, classifies E1 as a mass standard one level below E0, the national primary mass standard.
} 


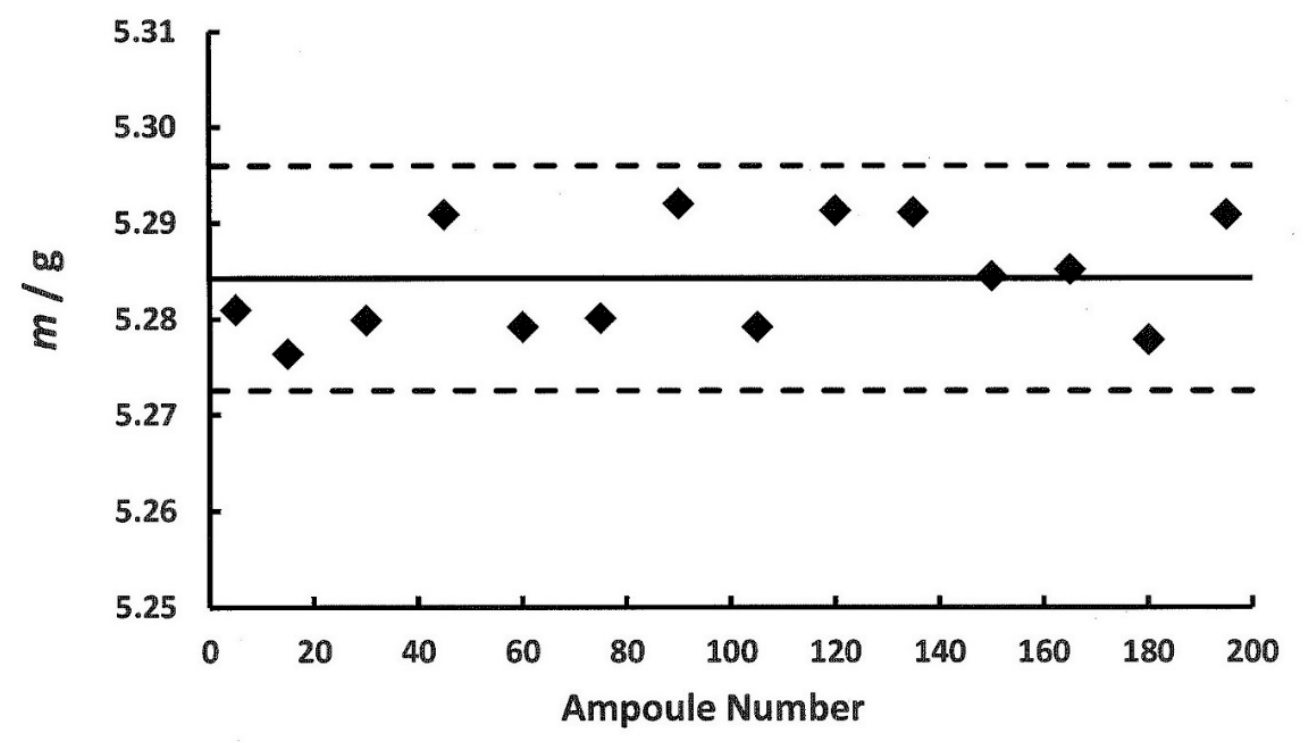

Fig. 4. Dispensed mass of master solution $m$ (in units of grams) in $5 \mathrm{~mL}$ aliquots of SRM 4321d as a function of ampoule filling order. The solid horizontal line corresponds to the mean mass (5.284 $3 \mathrm{~g}$ ), and the dashed lines represent the lower and upper limits for the \pm $2 s$ about the mean, where $s$ is the standard deviation for the $n=14$ distribution.

\section{Solution Massic Activities for SRM 4321d}

The massic activities in units of $\mathrm{Bq} \mathrm{g}{ }^{-1}$ for the ${ }^{234} \mathrm{U},{ }^{235} \mathrm{U}$, and ${ }^{238} \mathrm{U}$ isotopes in SRM 4321d were obtained from the values of the activity per unit mass of CRM 112-A (Table 1, col. 4) on multiplication by the mass ratio $m_{\mathrm{u}} / M_{\mathrm{s}}$, where $m_{\mathrm{u}}$ is the mass of the cleaned uranium metal, and $M_{\mathrm{s}}$ is the total solution mass. Refer to Fig. 3. Table 2 provides the certified values for the massic activities of the three uranium isotopes in the SRM solution along with their respective relative expanded uncertainties. A tabulation for the uncertainty assessment is given in Table 3. As indicated, the uncertainty in the respective half-life values dominates the massic activity uncertainties.

Table 2. Certified massic activities of ${ }^{234} \mathrm{U},{ }^{235} \mathrm{U}$, and ${ }^{238} \mathrm{U}$ in the natural uranium solution standard SRM 4321d. The uncertainties on these certified values are expanded uncertainties, $U=k u_{\mathrm{c}}$. The quantity $u_{\mathrm{c}}$ is the combined standard uncertainty that was calculated according to NIST and JCGM guidelines $[5,6]$. To obtain $U$, the combined standard uncertainty $u_{\mathrm{c}}$ was multiplied by a coverage factor of $k=2$, which was chosen to obtain an approximate $95 \%$ level of confidence. The uncertainty components that comprise $U$ are given in Table 3.

\begin{tabular}{|l|l|l|}
\hline $\begin{array}{l}\text { Uranium } \\
\text { isotope }\end{array}$ & Massic activity of isotope in SRM 4321d & Relative expanded uncertainty, $U(k=2)$ \\
\hline${ }^{234} \mathrm{U}$ & $220.16 \mathrm{~Bq} \mathrm{~g}^{-1}$ & $0.52 \%$ \\
\hline${ }^{235} \mathrm{U}$ & $10.540 \mathrm{~Bq} \mathrm{~g}^{-1}$ & $0.31 \%$ \\
\hline${ }^{238} \mathrm{U}$ & $228.93 \mathrm{~Bq} \mathrm{~g}^{-1}$ & $0.25 \%$ \\
\hline
\end{tabular}


Table 3. Uncertainty assessment for the massic activities of ${ }^{234} \mathrm{U},{ }^{235} \mathrm{U}$, and ${ }^{238} \mathrm{U}$ in in the natural uranium solution standard SRM 4321d, where $u$ in percent is the relative standard uncertainty for each component. All uncertainty components were evaluated by Assessment Type B, which denotes an evaluation by methods other than statistical methods [6, 7].

\begin{tabular}{|l|l|l|l|l|}
\hline \multirow{2}{*}{ Uncertainty component } & \multicolumn{2}{l|}{$u(\%)$} & ${ }^{238} U$ \\
\cline { 3 - 5 } & ${ }^{234} \mathrm{U}$ & ${ }^{235} \mathrm{U}$ & 0.003 \\
\hline 1 & Uranium mass fraction in CRM 112-A, from CRM 112-A Certificate [5] & 0.003 & 0.003 & 03 \\
\hline 2 & $\begin{array}{l}\text { Isotopic uranium atom fraction in CRM 112-A, from CRM 112-A } \\
\text { Certificate [5] }\end{array}$ & 0.077 & 0.0271 & 0.00020 \\
\hline 3 & Half-life [4] used for conversion of number of atoms to activity & 0.244 & 0.142 & 0.112 \\
\hline 4 & Mass of CRM 112-A uranium metal used & 0.05 & 0.05 & 0.05 \\
\hline 5 & Quantitative dissolution of metal & 0.05 & 0.05 & 0.05 \\
\hline 6 & Mass of SRM 4321d master solution & 0.005 & 0.005 & 0.005 \\
\hline Relative combined standard uncertainty, $\boldsymbol{u}_{\mathbf{c}}$ & $\mathbf{0 . 2 6 1}$ & $\mathbf{0 . 1 5 3}$ & $\mathbf{0 . 1 2 3}$ \\
\hline Relative expanded uncertainty $(\boldsymbol{k}=\mathbf{2}), \boldsymbol{U}$ & $\mathbf{0 . 5 2}$ & $\mathbf{0 . 3 1}$ & $\mathbf{0 . 2 5}$ \\
\hline
\end{tabular}

\section{Experimental Measurements Aspects}

\subsection{Homogeneity}

Homogeneity of the SRM 4321d master solution and among the filled and sealed ampoules was checked by photonic emission integral counting. Each and every ampoule was measured on one or two occasions in a $\mathrm{NaI}(\mathrm{Tl})$ well counter; viz., a PerkinElmer (Waltham, MA, USA) 2480 WIZARD2 Automatic Gamma Counter. The detector crystal was $75 \mathrm{~mm}$ diameter with $80 \mathrm{~mm}$ height and shielded with a minimum of $50 \mathrm{~mm}$ of lead. The 197 ampoules were measured in eight batches and were loaded into the well by the automatic sample changer using custom-built centering tubes. Each batch contained 30 ampoules, including blanks for background subtraction. The ampoules for a given batch were sampled by taking every fourth or fifth ampoule in the filling order. Stability amongst batches on the different measurement occasions was monitored with a $1.97 \mathrm{kBq}{ }^{129}$ I check source $\left(1.6 \times 10^{7}\right.$ a half-life). Although there are over 250 known $\gamma$ transitions in the three uranium isotopes and the three $\beta^{-}$-emitting daughters ${ }^{231} \mathrm{Th}$, ${ }^{234} \mathrm{Th}$, and $\left.{ }^{234 \mathrm{~m}} \mathrm{~Pa}\right)$, the $\mathrm{NaI}(\mathrm{Tl})$ spectra are rather uninteresting, with the decay fractionated through many weak transitions and dominated by the $\mathrm{K}$ and $\mathrm{L} \mathrm{X-rays} \mathrm{of} \mathrm{Th} \mathrm{and} \mathrm{Pa,} \mathrm{along} \mathrm{with} \mathrm{only} \mathrm{some} \mathrm{weak}$ higher-energy lines, principally from ${ }^{234 m} \mathrm{~Pa}$ decay. The spectrum for each measurement was accumulated for an interval of $2700 \mathrm{~s}$ (live time), and the region from nominal $20 \mathrm{keV}$ to $2000 \mathrm{keV}$ was integrated to obtain an integral counting rate that was corrected for background. The Poisson counting statistics on any one measurement were $0.15 \%$. The mean counting rate from 223 measurements was $191.89 \mathrm{~s}^{-1}$, with a relative standard deviation of $0.21 \%$. The average relative difference between 28 duplicate measurements on the same ampoules, randomly sampled from the entire set, was $0.16 \%$. The individual results are displayed in Fig. 5. Interestingly, but not surprisingly, $96 \%$ of the values lie within the mean $\pm 2 s$ interval, with only 8 of the 223 values falling outside. The normality of the homogeneity data was verified with a probability plot correlation coefficient (PPCC) test $(p \approx 0.64)$ [15]. The data also passed both an AndersonDarling goodness-of-fit test $(p \approx 0.28)$ and a Wilk-Shapiro test for normality $(p \approx 0.31)$. 


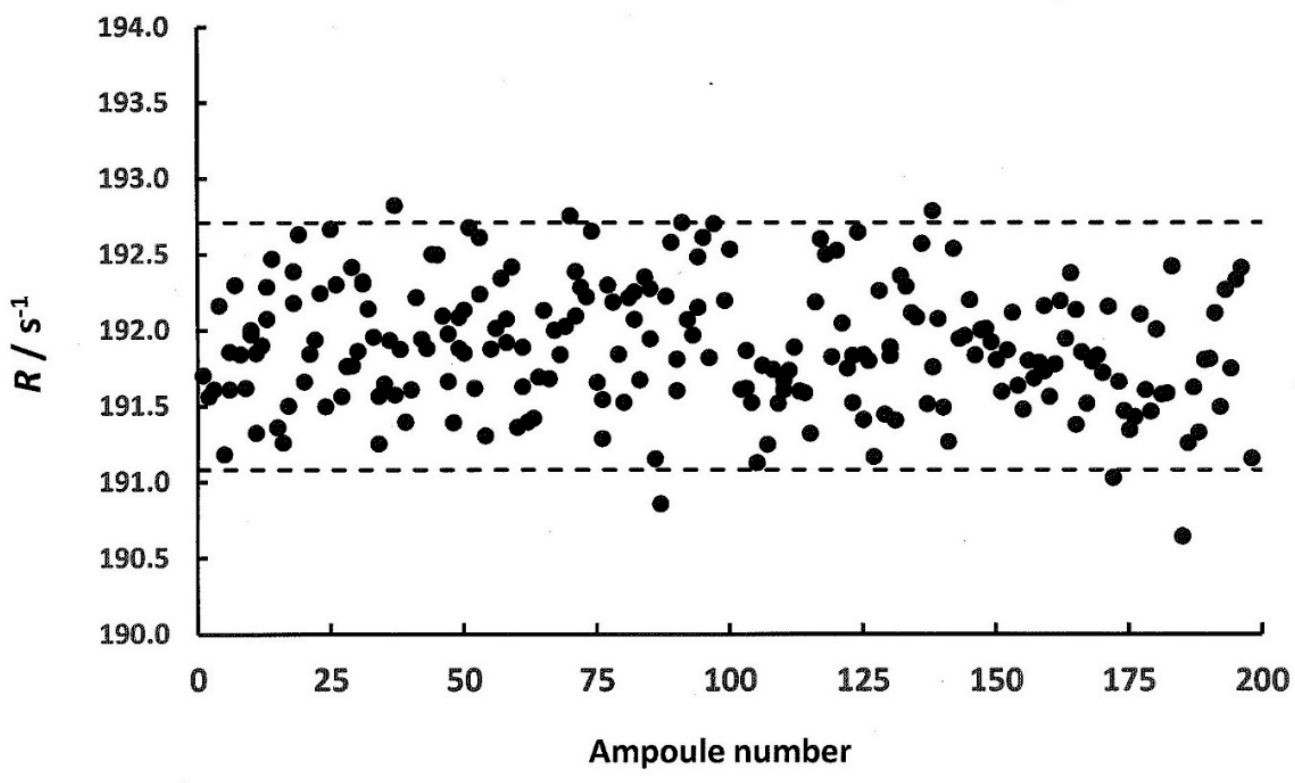

Fig. 5. The background-corrected integral counting rate $R$ (in units of counts per second) for each of 195 SRM 4321d ampoules plotted versus ampoule number (filling order) as measured in a $\mathrm{NaI}(\mathrm{Tl})$ well counter. The dashed lines show the mean $\pm 2 s$ interval, where $s$ is the standard deviation of the distribution for the $n=223$ measurements. Twenty-eight ampoules were measured in duplicate, with a $0.16 \%$ average relative difference.

\subsection{Impurities}

The CRM 112-A stock metal was certified to have an elemental purity of (99.975 \pm 0.006$) \%$ on a mass basis [5]. Also, as reported, ${ }^{233} \mathrm{U}$ and ${ }^{236} \mathrm{U}$ "were not detected" [5], and the limit of detection of uranium ratios for the techniques that were used was stated to be $5 \times 10^{-9}$.

Impurity analyses of the SRM 4321d solution were also performed by high-resolution photonic emission spectrometry using high-purity germanium (HPGe) detectors. For this, the contents of one of the SRM ampoules were transferred gravimetrically to a NIST "standard ampoule," which is used to define the geometry and attenuation for all ionization chamber and $\gamma$-ray spectrometry measurements performed at NIST. Measurements, ranging in length between $1 \mathrm{~d}$ and $2 \mathrm{~d}$, were made with three detectors (viz., "T," "B," and "X") in different geometries. The detectors and spectrometry procedures used by NIST have been described by Pibida et al. [16, 17].

No photon-emitting impurities were observed in any of the measurements. The estimated lower limits of detection for the $\mathrm{X}$ detector, expressed as massic photon emission rate, as of April 2017, were:

$1.4 \mathrm{~s}^{-1} \mathrm{~g}^{-1}$ for $15 \mathrm{keV}<E<20 \mathrm{keV}$;

$0.36 \mathrm{~s}^{-1} \mathrm{~g}^{-1}$ for $25 \mathrm{keV}<E<105 \mathrm{keV}$;

$0.25 \mathrm{~s}^{-1} \mathrm{~g}^{-1}$ for $110 \mathrm{keV}<E<490 \mathrm{keV}$; and

$0.32 \mathrm{~s}^{-1} \mathrm{~g}^{-1}$ for $500 \mathrm{keV}<E<2000 \mathrm{keV}$.

These limits are in the range of $0.03 \%$ to $0.15 \%$ relative to the total massic activity of the three uranium isotopes and their daughters, assuming an impurity with $100 \%$ emission of a single photon.

These impurity analyses were formidable tasks, given the large number of weak $\gamma$ transitions and intense Th and Pa K and L X-rays. Similarly, it was difficult to perform accurate assays of the three uranium isotopes from the $\gamma$-ray spectrometry. The assays had estimated relative standard uncertainties in the range of $15 \%$ to $30 \%$, and the ${ }^{238} \mathrm{U}$ and ${ }^{234} \mathrm{U}$ results compared to the certified massic activities were consistent to only $7.4 \%$ and $29 \%$, respectively. By fortuity, the assay result for ${ }^{235} \mathrm{U}$, with lowest massic activity, agreed with the certified value to better than $0.1 \%$ ! The large measurement uncertainties are not 
from the uncertainties in the nuclear decay data, but rather they come from the low counting statistics resulting from the very small magnitudes in the probabilities per decay for the photons.

Alpha spectrometry for impurities was also performed as a part of the isotope dilution analysis. No impurities were detected, as considered and discussed in Sec. 4.3.2.

\subsection{Confirmatory Measurements on SRM 4321d}

\subsubsection{Liquid Scintillation Counting}

Confirmatory measurements for the total massic activity in SRM 4321d were performed by $4 \pi \alpha \beta$ liquid scintillation (LS) counting. Two separate trials were conducted. Each set of sources for the trials was measured on two different LS counters; viz., Beckman LS 6500 (Beckman Coulter, Fullerton, CA, USA), designated as counter "B"; and Hitachi Accuflex LSC-8000 (Hitachi Aloka Medical, Ltd., Tokyo, Japan), designated as counter "H." More than one LS counter is typically used in our laboratory for any given set of experiments to hopefully demonstrate that results are independent of the operating characteristics of a particular instrument (detection threshold, photomultiplier efficiency, deadtime, amplification, signal conversion, etc.). In addition to our laboratory's common practice of closely matching quenching conditions and cocktail compositions in counting sources, both instruments use quench indicating parameters (QEP) to monitor quenching. The Beckman counter "B" uses a Horrocks Number H\# to monitor the quench level, which is based on the downward spectrum shift of the Compton edge of an external ${ }^{137} \mathrm{Cs}$ source with increasing quenching in the cocktail, while the Hitachi counter " $\mathrm{H}$ " uses the less reliable external standard channel ratio (ESCR) quench parameter, which relates quenching to the ratio of two counting windows in the Compton spectrum of ${ }^{133} \mathrm{Ba}$.

The LS counting sources were in all cases gravimetrically prepared in $20 \mathrm{~mL}$ glass LS vials with Ultima Gold AB (UGAB) scintillation fluid (PerkinElmer, Waltham, MA, USA). Aliquots from randomly selected ampoules of SRM 4321d as dispensed with a polyethylene aspirating pycnometer were measured on an electronic microbalance (Mettler AT20). Other cocktail components were weighed with a mechanical analytical balance (Mettler B5). To match aqueous mass fractions, $f_{\text {aq, }}$, additional amounts of nominal 1 mol $\mathrm{L}^{-1} \mathrm{HNO}_{3}$ were added to some cocktails. Blank sources (for subsequent background subtraction) of similar composition over the same quench range were also prepared.

The LS rate from a counting source of natural uranium must be considered before addressing the details for the two trials. To a very good, first approximation, the LS counting rate $R$ for cocktails of the SRM 4321d uranium solution, integrated over the entire spectrum, can be estimated to be:

$$
R=m_{U}\left[A_{234 U} \varepsilon_{234 U}+A_{235 U}\left(\varepsilon_{235 U}+\varepsilon_{231 T h}\right)+A_{238 U}\left(\varepsilon_{238 U}+\varepsilon_{234 T h}+\varepsilon_{234 m P a}\right)\right],
$$

where $m_{U}$ is the aliquot mass of the uranium solution in the source; $A_{234 U}, A_{235 U}$, and $A_{238 U}$ are the massic activities of the ${ }^{234} \mathrm{U},{ }^{235} \mathrm{U}$, and ${ }^{238} \mathrm{U}$ isotopes, respectively; and $\varepsilon_{234 U}, \varepsilon_{235 U}, \varepsilon_{231 T h}, \varepsilon_{238 U}$, $\varepsilon_{234 T h}$, and $\varepsilon_{234 \mathrm{mPa}}$ are the respective LS detection efficiencies for ${ }^{234} \mathrm{U},{ }^{235} \mathrm{U},{ }^{231} \mathrm{Th},{ }^{238} \mathrm{U},{ }^{234} \mathrm{Th}$, and ${ }^{234 \mathrm{~m}} \mathrm{~Pa}$. Refer to Fig. 1 for placement of these nuclides in the decay chains.

The efficiency for each of the three $\alpha$-emitting uranium isotopes can be taken to be unity, since the $\alpha$ particles are detected with $100 \%$ efficiency in $4 \pi$ geometry, and it has been demonstrated by Fitzgerald [18] that there is negligible, $<0.01 \%$, wall effect loss in LS counting with $\alpha$ emitters.

The three $\beta^{-}$-emitting radionuclides were expected to have reasonably high detection efficiencies, but they still required separate evaluations and determinations. This can be achieved by efficiency calculations with free-parameter models using computational codes that are employed for the CNET ${ }^{6}$ method [19]. Generally, the efficiency calculations for a given radionuclide are linked through the free parameter to that for ${ }^{3} \mathrm{H}$ as an efficiency monitor. The ${ }^{231} \mathrm{Th},{ }^{234} \mathrm{Th}$, and ${ }^{234 \mathrm{~m}} \mathrm{~Pa}$ nuclides all have extremely complicated decay schemes, with many $\beta^{-}$branches and numerous $\gamma$ transitions and crossovers, all of which requires

\footnotetext{
${ }^{6}$ The acronym CNET refers to the CIEMAT/NIST Efficiency Tracing method. CIEMAT/NIST refers to the two laboratories that collaborated in developing the protocol for this LS tracing methodology, i.e., the Centro de Investigaciones Energéticas, Medioambientales y Tecnológicas (CIEMAT) and the National Institute of Standards and Technology (NIST).
} 
considerable input data; e.g., the branching ratios and $\beta^{-}$spectrum for each branch, along with the probability per decay and conversion coefficients for each $\gamma$, and accompanying atomic data for the conversion electrons and rearrangement processes. In order to create manageable input data files, the decay scheme for each of the three nuclides was simplified by considering only branches with greater than $1 \%$ probability of the total decay, with renormalizations of the probabilities per decay for the simplification.

For these calculations, the LS counting efficiencies for ${ }^{231} \mathrm{Th}$, ${ }^{234} \mathrm{Th}$, and ${ }^{234 \mathrm{~m}} \mathrm{~Pa}$ were calculated for an assumed cocktail of $1 \mathrm{~mL}$ of water in $10 \mathrm{~mL}$ of Ultima Gold using the 2011 version of the MICELLE2 code [20, 21] with Birks parameter, $k B$, of $0.0075 \mathrm{MeV} \mathrm{cm}^{-1}$. The composition of the scintillator and functional form of the electron stopping power for Ultima Gold were used as given in the data files that accompany the MICELLE2 code. The nuclear decay data used as input were derived from simplified level schemes as mentioned above, using DDEP recommended data files [1] for each nuclide. Individual L-shell and total M-shell conversion probabilities were calculated using the BrICC code using the frozen orbital approximation [22]. In all, a single $\beta^{-}$branch was calculated for ${ }^{234 \mathrm{~m}} \mathrm{~Pa}$, whereas one $\beta^{-}$, two $\beta^{-} \gamma$, and two $\beta^{-} \gamma \gamma$ cascades were calculated for ${ }^{234} \mathrm{Th}$, and four $\beta^{-} \gamma$ and two $\beta^{-} \gamma \gamma$ cascades were considered for ${ }^{231} \mathrm{Th}$. The efficiencies for the individual results were renormalized and summed to give a total efficiency for each isotope. The computational results for these efficiencies as a function of the ${ }^{3} \mathrm{H}$ efficiency are shown in Fig. 6. For comparison, at a relatively unquenched level of $50 \%{ }^{3} \mathrm{H}$ efficiency $\left(\varepsilon_{3}=0.50\right)$, the corresponding efficiencies for ${ }^{231} \mathrm{Th},{ }^{234} \mathrm{Th}$, and ${ }^{234 \mathrm{~m}} \mathrm{~Pa}$ are $0.901,0.916$, and 0.998 , respectively. Because of the decay scheme simplifications, the calculated efficiencies are not expected to be accurate to better than $1 \%$ to $2 \%$.

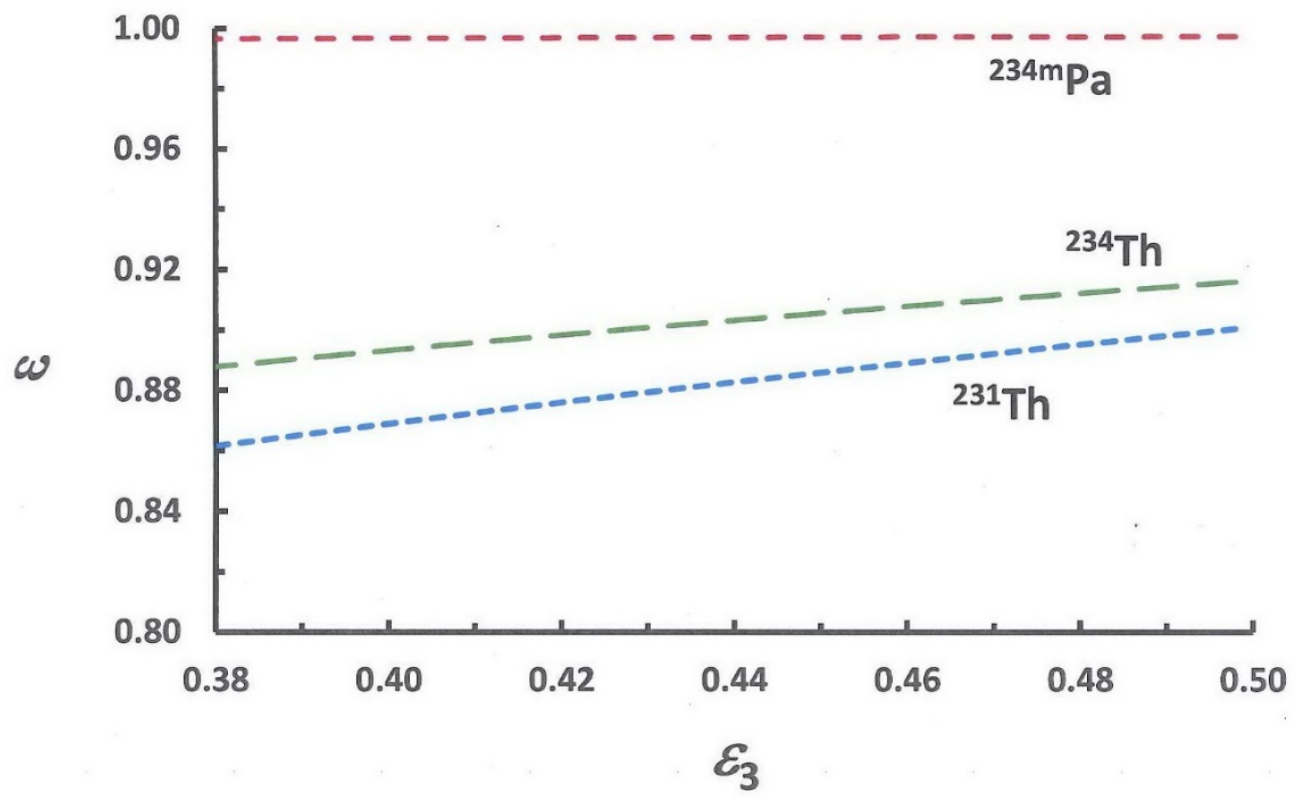

Fig. 6. Computed LS detection efficiencies $\varepsilon$ for the uranium-isotope daughters, ${ }^{234 \mathrm{~m}} \mathrm{~Pa}$, ${ }^{234} \mathrm{Th}$, and ${ }^{231} \mathrm{Th}$, as a function of the efficiency for ${ }^{3} \mathrm{H}$ as obtained with the MICELLE2 code.

For the first trial, a preliminary evaluation of the total massic activity of the SRM solution by LS spectrometry was performed using three different cocktail compositions with UGAB scintillation fluid. This was intended to evaluate the effects of chemical quenching by varying aqueous fractions $f_{\text {aq }}$ (by the addition of dilute $\mathrm{HNO}_{3}$ ), and the effects of color quenching by varying the mass of the yellow SRM solution. Three replicate sources were prepared for each of the three series, along with matched blanks for background subtraction. Each source consisted of a cocktail with about $9.8 \mathrm{~g}$ of UGAB, an aliquot of the SRM solution, and blank $\mathrm{HNO}_{3}$ with the approximate amount-of-substance concentration of the SRM solution. In addition, approximately $60 \mathrm{mg}$ of di-(2-ethylhexyl)phosphoric acid (DEHPA or HDEHP), 
$\left(\mathrm{C}_{8} \mathrm{H}_{17} \mathrm{O}\right)_{2} \mathrm{PO}_{2} \mathrm{H}$, which is a complexing agent, was added to each cocktail. Its use here was intended to complex the uranyl ions in the cocktail. The total cocktail mass for each source was held constant.

These sources were measured in both LS spectrometers, for $n=4$ cycles in counter "B" and $n=3$ cycles in counter "H." Each measurement was conducted for a live-time interval of $3600 \mathrm{~s}$, with a relative Poisson statistical "counting error" in the range of $0.08 \%$ to $0.12 \%$. These results are tabulated in Table 4, showing the grand mean averages of the massic counting rates $\left(R_{\mathrm{U}} / \mathrm{m}\right)$ for the three series in the two counters. The computed relative precision estimator $S$ considers both within-source and between-source components of variance. The within-source component is a "typical" value of the standard deviation of the mean, $s_{\mathrm{m}}$, on the $n=4$ or $n=3$ replicate measurements of a given source, where the typical value is taken to be the average of the mean and median of the $n s_{\mathrm{m}}$ values. The between-source component is the standard deviation for the mean values of the three sources. The two components are combined in quadrature to form $S$. Quenching, as reflected in the average quench-indicating parameter $H \#$, maps with the source composition variations shown in Table 5 and clearly scales more strongly with the aliquot mass (affecting color and $\mathrm{UO}_{2}{ }^{+2}$ ion content) than with the aqueous fraction. Nevertheless, the massic counting rates are not strongly influenced by quenching because of the efficiency invariance for the three $\alpha$ emitters and the high detection efficiencies for the ${ }^{231} \mathrm{Th},{ }^{234} \mathrm{Th}$, and ${ }^{234 \mathrm{~m}} \mathrm{~Pa} \beta^{-}$emitters.

Table 4. LS counting results for the first trial as obtained in the two counters. The average quench-indicating parameter $H \#$ (measured in counter "B") maps with the composition variations shown in Table 5 . Values for the massic counting rate $R_{\mathrm{U}} / m$ are grand mean averages for the three sources for each series and across the $n=4$ (for "B") or $n=3$ (for "H") replicate measurements for each source. The relative measurement precision estimator $S$ is the combination in quadrature of the typical within-source standard deviation of the mean for the three sources and the between-source standard deviation of the three mean values.

\begin{tabular}{|l|l|l|l|l|l|}
\hline \multirow{2}{*}{ Series } & \multirow{2}{*}{ Average $H \#$} & \multicolumn{2}{|l|}{ "B" counter } & "H" counter \\
\cline { 3 - 6 } & & $\left.R_{\mathrm{U}} / \mathrm{m}^{-1} \mathrm{~s}^{-1}\right)$ & $S(\%)$ & $R_{\mathrm{U}} / \mathrm{m}^{-1}\left(\mathrm{~s}^{-1} \mathrm{~g}^{-1}\right)$ & $S(\%)$ \\
\hline A & 104.2 & 905.5 & 0.17 & 906.9 & 0.56 \\
\hline B & 120.0 & 904.5 & 0.10 & 905.0 & 0.14 \\
\hline C & 122.9 & 903.9 & 0.11 & 905.0 & 0.62 \\
\hline
\end{tabular}

It was estimated that the equivalent ${ }^{3} \mathrm{H}$ efficiency in the three series is in the range of about $40 \%$ to $45 \%$. From the MICELLE2 calculations (Fig. 6), the efficiencies are estimated to be $\varepsilon 231 \mathrm{Th}=0.869$, $\varepsilon 234 \mathrm{Th}=0.893$, and $\varepsilon 234 \mathrm{mPa}=0.997$ at a tritium efficiency $\varepsilon 3=0.40$; and $\varepsilon_{231 \mathrm{Th}}=0.886, \varepsilon 234 \mathrm{Th}=0.906$, and $\varepsilon 234 \mathrm{mPa}=0.997$ at a tritium efficiency of $\varepsilon_{3}=0.45$. Using these values in Eq. (2) along with the certified massic activities for each of the three uranium isotopes (Table 2) gives calculated values of

$\left(R_{\mathrm{U}} / m\right)_{\text {calc }}=901.5 \mathrm{~s}^{-1} \mathrm{~g}^{-1}$ at equivalent $\varepsilon_{3}=0.40$, and

$\left(R_{\mathrm{U}} / \mathrm{m}\right)_{\mathrm{calc}}=904.6 \mathrm{~s}^{-1} \mathrm{~g}^{-1}$ at equivalent $\varepsilon_{3}=0.45$, which can be compared to the average measured values in Table 4, which range from $904 \mathrm{~s}^{-1} \mathrm{~g}^{-1}$ to $907 \mathrm{~s}^{-1}$ $\mathrm{g}^{-1}$. The agreement is substantial, which confirms the total massic activity in SRM 4321d as derived from the isotopic atom percentages for metallic CRM 112-A.

Table 5. Characteristics of the LS counting sources for the first LS trial in terms of preparation details. Each series consisted of three replicate sources. The three series include variations in mass of the SRM aliquot (affecting $\mathrm{UO}_{2}{ }^{+2}$ ion content and color) and the aqueous fraction $f_{\mathrm{aq}}$. The aqueous part of $f_{\text {aq }}$ consisted of a nominal $1 \mathrm{~mol} \mathrm{~L}^{-1} \mathrm{HNO}_{3}$ in all cases. The values for the masses and $f_{\text {aq }}$ are averages for the three sources in the series. Each cocktail also contained approximately $60 \mathrm{mg}$ of the HDEHP complexing agent.

\begin{tabular}{|l|l|l|l|l|l|}
\hline Series & Mass of UGAB (g) & $\begin{array}{l}\text { Mass of blank } \\
\mathrm{HNO}_{3}(\mathrm{~g})\end{array}$ & $\begin{array}{l}\text { Aliquot mass of SRM } \\
\text { solution }(\mathrm{g})\end{array}$ & $\begin{array}{l}\text { Total cocktail } \\
\text { mass }(\mathrm{g})\end{array}$ & $f_{\text {aq }}(\%)$ \\
\hline $\mathrm{A}$ & 9.804 & 0.620 & 0.221 & 10.70 & 7.86 \\
\hline $\mathrm{B}$ & 9.804 & 0.483 & 0.424 & 10.77 & 8.43 \\
\hline $\mathrm{C}$ & 9.629 & 0.619 & 0.419 & 10.72 & 9.67 \\
\hline
\end{tabular}

The second LS counting trial was designed to more definitely determine the efficiencies of the three $\beta^{-}$-emitting nuclides in prepared cocktails. In order to link the efficiencies of these nuclides to a ${ }^{3} \mathrm{H}$ efficiency, $\varepsilon_{3}$, it was necessary to know what $\varepsilon_{3}$ would be in a uranium cocktail at its level of quenching, i.e., to determine the tritium efficiency in a cocktail with a composition matching that in a uranium 
counting source with large $\mathrm{UO}_{2}{ }^{+2}$ ion loading and color quenching. This was achieved by preparing a mixed $\mathrm{U} /{ }^{3} \mathrm{H}$ cocktail using measured aliquots of the natural uranium SRM solution and a tritiated water standard (SRM 4926e) [23]. The counting rate $R_{\mathrm{UT}}$ for this mixed cocktail can be given by

$$
R_{\mathrm{UT}}=m_{\mathrm{U}}\left(\frac{R_{u}}{m}\right)+\varepsilon_{\mathrm{T}} m_{\mathrm{T}} A_{\mathrm{T}},
$$

where $m_{\mathrm{U}}$ is the mass of the uranium aliquot, $\left(R_{\mathrm{U}} / m\right)$ is the massic counting rate for a matched pure uranium cocktail, and $\varepsilon_{\mathrm{T}}, m_{\mathrm{T}}$, and $A_{\mathrm{T}}$ are the ${ }^{3} \mathrm{H}$ counting efficiency, the mass of the ${ }^{3} \mathrm{H}$ standard aliquot, and the massic activity of the ${ }^{3} \mathrm{H}$ standard in the mixed cocktail, respectively. Rearrangement gives

$$
\varepsilon_{\mathrm{T}}=\frac{R_{\mathrm{UT}}-m_{\mathrm{U}}\left(\frac{R u}{m}\right)}{m_{\mathrm{T}} A_{\mathrm{T}}} .
$$

With this, it is possible to obtain the equivalent tracing efficiency for ${ }^{3} \mathrm{H}$, which can be used to determine the LS detection efficiencies for the ${ }^{231} \mathrm{Th},{ }^{234} \mathrm{Th}$, and ${ }^{234 \mathrm{~m}} \mathrm{~Pa} \beta^{-}$emitters from the MICELLE2 calculations. This value of $\varepsilon_{\mathrm{T}}$ is the equivalent ${ }^{3} \mathrm{H}$ efficiency in a cocktail of composition matching the uranium cocktails.

Table 6 provides the characteristics of the sources used for this second LS trial to obtain $\varepsilon_{\mathrm{T}}$ in a quenched uranium cocktail. The counting results for these sources, given in Table 7, could in turn be used to calculate the detection efficiencies for the ${ }^{231} \mathrm{Th},{ }^{234} \mathrm{Th}$, and ${ }^{234 \mathrm{~m}} \mathrm{~Pa} \beta^{-}$emitters using the MICELLE2 calculations (Fig. 6).

Table 6. Characteristics of the LS counting sources for the second LS trial in terms of preparation details. There were three replicate cocktails for the uranium sources. The masses given here for them are the averages for the three, and the values in parentheses correspond to their standard deviation of the means. Only one source was prepared for each tritium cocktail (T), the mixed uranium $\mathrm{U} /{ }^{3} \mathrm{H}$ cocktail (UT), and for a blank (B). Each cocktail also contained approximately $60 \mathrm{mg}$ of the HDEHP complexing agent.

\begin{tabular}{|l|l|l|l|l|l|l|}
\hline Cocktail & $\begin{array}{l}\text { Mass of } \\
\mathrm{UGAB}(\mathrm{g})\end{array}$ & $\begin{array}{l}\text { Mass of blank } \\
\mathrm{HNO}_{3}(\mathrm{~g})\end{array}$ & $\begin{array}{l}\text { Aliquot mass of } \\
\text { SRM solution }(\mathrm{g})\end{array}$ & $\begin{array}{l}\text { Aliquot mass of } \\
{ }^{3} \mathrm{H} \text { standard }(\mathrm{g})\end{array}$ & $\begin{array}{l}\text { Total cocktail } \\
\text { mass }(\mathrm{g})\end{array}$ & $f_{\text {aq }}(\%)$ \\
\hline $\mathrm{U}(n=3)$ & $9.8495(28)$ & 0 & $0.2132(12)$ & 0 & $10.1758(19)$ & $2.638(10)$ \\
\hline $\mathrm{T}$ & 9.8573 & 0.2251 & 0 & 0.04701 & 10.1377 & 2.684 \\
\hline $\mathrm{UT}$ & 9.8458 & 0 & 0.2088 & 0.04705 & 10.1098 & 2.531 \\
\hline $\mathrm{B}$ & 9.8583 & 0.2505 & 0 & 0 & 10.2192 & 2.960 \\
\hline
\end{tabular}

Table 7. LS counting results for the second trial as obtained in the two counters. The H\# quench-indicating parameter (measured in counter "B") maps with the composition variations given in Table 6 and shows the close matching between the three uranium U cocktails (U) and the mixed $\mathrm{U} /{ }^{3} \mathrm{H}$ cocktail (UT). The pure ${ }^{3} \mathrm{H}$ cocktail (T) is less quenched because of the absence of uranyl nitrate ions and the yellow coloring present in the other cocktails. It also reflects a higher tritium efficiency. Values for the massic counting rate $\left(R_{\mathrm{U}} / \mathrm{m}\right)$ are grand mean averages for the three $\mathrm{U}$ sources, and the values in parentheses are the standard deviations of the mean for the $n=3$ sources. The values of $R_{\mathrm{UT}}, m_{\mathrm{U}}, m_{\mathrm{at}}$, and $\varepsilon_{\mathrm{T}}$ for the UT cocktail were used to obtain $\varepsilon_{\mathrm{T}}$ from Eq. (4). The efficiencies for the three $\beta^{-}$-emitting isotopes were obtained from the MICELLE2 calculations (Fig. 6) for the determined value of $\varepsilon_{\mathrm{T}}$. The calculated value of $\left(R_{\mathrm{U}} / \mathrm{m}\right)_{\text {calc }}$ was in turn obtained from Eq. (2) using these efficiencies and the certified isotopic massic activities (Table 2). The

\begin{tabular}{|c|c|c|c|c|}
\hline Cocktails & $\mathrm{H \#}$ & Quantity & "B" counter & "H" counter \\
\hline $\mathrm{U}(n=3)$ & $78.6(8)$ & $\left(R_{\mathrm{U}} / m\right)$ & $910.70(34) \mathrm{s}^{-1} \mathrm{~g}^{-1}$ & $910.16(29) \mathrm{s}^{-1} \mathrm{~g}^{-1}$ \\
\hline $\mathrm{T}$ & 59.5 & $\varepsilon_{3}$ & 0.4906 & 0.4755 \\
\hline UT & \multirow{8}{*}{77.7} & $R_{\mathrm{UT}}$ & $276.61 \mathrm{~s}^{-1}$ & $225.54 \mathrm{~s}^{-1}$ \\
\hline UT & & $m_{\mathrm{U}}$ & $0.20883 \mathrm{~g}$ & $0.20883 \mathrm{~g}$ \\
\hline UT & & $m_{\mathrm{T}} A_{\mathrm{T}}$ & $82.471 \mathrm{~Bq}$ & $82.471 \mathrm{~Bq}$ \\
\hline UT & & $\varepsilon_{\mathrm{T}}$ & 0.442 & 0.431 \\
\hline UT & & $\varepsilon_{231 \mathrm{Th}}$ & 0.883 & 0.880 \\
\hline UT & & $\varepsilon_{234 \mathrm{Th}}$ & 0.904 & 0.901 \\
\hline UT & & $\varepsilon_{234 \mathrm{mPa}}$ & 0.997 & 0.997 \\
\hline UT & & $\left(R_{\mathrm{U}} / m\right)_{\text {calc }}$ & $904.1 \mathrm{~s}^{-1} \mathrm{~g}^{-1}$ & $903.4 \mathrm{~s}^{-1} \mathrm{~g}^{-1}$ \\
\hline $\begin{array}{l}\text { U/UT } \\
\end{array}$ & - & $\delta$ & $0.73 \%$ & $0.75 \%$ \\
\hline
\end{tabular}
relative difference between the measured $\left(R_{\mathrm{U}} / \mathrm{m}\right)$ value and calculated $\left(R_{\mathrm{U}} / m\right)_{\text {calc }}$ value is given as $\delta$.

The three uranium $\mathrm{U}$ cocktails (U) and the mixed $\mathrm{U}^{3} \mathrm{H}$ cocktail (UT) were closely matched, as reflected in the compositions given in Table 6 and the $H \#$ quench-indicating parameters, thus validating the 
approach. The pure ${ }^{3} \mathrm{H}$ cocktail (T), prepared merely for comparison purposes, was less quenched because of the absence of uranyl nitrate ions and the yellow coloring that was present in the other cocktails, and this is also reflected in its greater detection efficiency. With these reasonably well determined efficiencies, values of $\left(R_{\mathrm{U}} / \mathrm{m}\right)_{\text {calc }}$ obtained for the certified isotopic massic activities could be compared to measured values of $\left(R_{\mathrm{U}} / \mathrm{m}\right)$, as shown in Table 7 . The agreement is about $0.75 \%$, which is about as good as could be expected given the assumptions for the MICELLE2 calculations.

\subsubsection{Isotope Dilution Analysis}

A more rigorous confirmation of the certified massic activity values for SRM 4321d was performed by $\alpha$-particle spectrometry using an isotope dilution analysis procedure, with a ${ }^{232} \mathrm{U}$ standard as a tracer to determine ${ }^{234} \mathrm{U}$ and ${ }^{238} \mathrm{U}$.

The solution used for the isotope dilution procedure was a gravimetric dilution of one randomly selected SRM 4321d ampoule. A dilution factor of $D=6.7148 \pm 0.0026$ was determined by measuring both the dispensed and contained masses of the SRM solution and a nominal $1.8 \mathrm{~mol} \mathrm{~L}^{-1} \mathrm{HNO}_{3}$ diluent. The resulting solution had a density of $(1.062 \pm 0.005) \mathrm{g} \mathrm{mL}^{-1}$ and an amount-of-substance concentration of about $1.8 \mathrm{~mol} \mathrm{~L}^{-1} \mathrm{HNO}_{3}$, and it contained about $3.1 \mathrm{mg} \mathrm{UO}_{2}{ }^{+2}$ per gram of solution. The preparation was performed with a polyethylene aspirating pycnometer, and both components were weighed with a Mettler AT20 electronic microbalance. The relative difference in contained and dispensed masses for the SRM aliquot was $0.017 \%$, and that for the total solution mass was $0.007 \%$.

Four replicate counting sources were prepared as follows:

Aliquots of the SRM 4321d dilution, in the range of $26 \mathrm{mg}$ to $28 \mathrm{mg}$, were gravimetrically added to 20 $\mathrm{mL}$ glass vessels, adding an approximately equal mass of ${ }^{232} \mathrm{U}$ standard tracer (SRM 4324B) [24]. The massic activities of ${ }^{232} \mathrm{U},{ }^{234} \mathrm{U}$, and ${ }^{238} \mathrm{U}$ were all in the $32 \mathrm{~Bq} \mathrm{~g}^{-1}$ to $34 \mathrm{~Bq} \mathrm{~g}^{-1}$ range. One blank with the same ${ }^{232} \mathrm{U}$ tracer was also prepared. Another sample of the diluted SRM solution without ${ }^{232} \mathrm{U}$ tracer was prepared to check for $\alpha$-emitting impurities. Each sample then received about $90 \mathrm{mg}$ of $0.42 \mathrm{~mol} \mathrm{~L}^{-1}$ $\mathrm{NaHSO}_{4}$ and $1 \mathrm{~mL}$ of $2 \mathrm{~mol} \mathrm{~L}^{-1} \mathrm{HNO}_{3}$ to prevent the formation of insoluble oxides that can be difficult to re-dissolve in a subsequent evaporation step. All samples were evaporated to dryness and re-dissolved with heating in about $5 \mathrm{~mL}$ of a nominal $3 \mathrm{~mol} \mathrm{~L}^{-1} \mathrm{HNO}_{3}$ solution. The ${ }^{232} \mathrm{U}$ tracer solution contains its decay product ${ }^{228} \mathrm{Th}$, which has $\alpha$-particle energies close to those of ${ }^{232} \mathrm{U}$, in radioactive equilibrium; viz., 5436 $\mathrm{keV}(26 \%)$ and $5520 \mathrm{keV}$ (73\%) for ${ }^{228} \mathrm{Th}$, and $5355 \mathrm{keV}$ (31\%) and $5413 \mathrm{keV}(69 \%)$ for ${ }^{232} \mathrm{U}$ [4]. To diminish the overlapping of the detection signals of ${ }^{232} \mathrm{U}$ and ${ }^{228} \mathrm{Th}$ in the $\alpha$ spectra, a purification of the uranium fraction was necessary to eliminate the ${ }^{228} \mathrm{Th}$.

Uranium was separated from thorium using extraction chromatography with UTEVA (Uranium und TEtraValents Actinides) resin (EiChrom, Inc., Lisle, IL, USA). About $125 \mathrm{mg}$ of a $\mathrm{Zr}(\mathrm{IV})$ solution (100 $\mu \mathrm{g}$ $\mathrm{Zr} / \mathrm{mL}$ as nitrate in $2 \mathrm{~mol} \mathrm{~L}^{-1} \mathrm{HNO}_{3}$ ) were added as a nonisotopic carrier for ${ }^{228} \mathrm{Th}$ to the $5 \mathrm{~mL}$ of $3 \mathrm{~mol} \mathrm{~L}^{-1}$ $\mathrm{HNO}_{3}$ sample solution to facilitate the ${ }^{228} \mathrm{Th}$ separation [25]. Each sample solution containing the ${ }^{232} \mathrm{U}$ tracer was passed through a UTEVA column with $2 \mathrm{~mL}$ bed volume, preconditioned with $3 \mathrm{~mol} \mathrm{~L}^{-1} \mathrm{HNO}_{3}$. The resin (retaining uranium and thorium) was rinsed with $20 \mathrm{~mL}$ of $3 \mathrm{~mol} \mathrm{~L}^{-1} \mathrm{HNO}_{3}$ (with excess $\mathrm{Zr}$ and ${ }^{228} \mathrm{Th}$ progeny being eluted), and then $20 \mathrm{~mL}$ of $6 \mathrm{~mol} \mathrm{~L}^{-1} \mathrm{HCl}$ was passed to elute ${ }^{228} \mathrm{Th}$. The uranium fraction was subsequently stripped from the column with $20 \mathrm{~mL}$ to $25 \mathrm{~mL}$ of $0.01 \mathrm{~mol} \mathrm{~L}^{-1} \mathrm{HCl}$. After addition of $2 \mathrm{~mL}$ of $0.42 \mathrm{~mol} \mathrm{~L}^{-1} \mathrm{NaHSO}_{4}$ to the uranium strip solutions, and evaporation and fuming with concentrated $\mathrm{HNO}_{3}$ and $\mathrm{HClO}_{4}$ to decompose the resin's organic matter, the purified uranium fractions were electrodeposited onto stainless-steel disks from an electrolyte of sodium hydrogen sulfate-sodium sulfate buffer $\left(\mathrm{NaHSO}_{4} / \mathrm{Na}_{2} \mathrm{SO}_{4}\right.$ amount-of-substance ratio $\left.=0.194, \mathrm{pH}=2.6\right)$.

The electrodeposited uranium sources were measured with EG\&G Ortec Octete alpha spectrometers (Oak Ridge TN, USA), having $450 \mathrm{~mm}^{2}$ planar, ion-implanted Si detectors. Thin films prepared from collodion were interposed between sources and detectors to prevent recoil contamination of the detectors by ${ }^{232} \mathrm{U}$ progeny [26]. The sample sizes were chosen to produce sources with approximately $1 \mathrm{~Bq}$ each of ${ }^{234} \mathrm{U}$ and ${ }^{238} \mathrm{U}$ and a source deposit thickness (as uranium oxide) of no more than about $60 \mu \mathrm{g} \mathrm{cm}{ }^{-2}$, to minimize $\alpha$ energy straggling in the source. The samples were typically counted for about $2 \mathrm{~d}$ to obtain good Poisson counting statistics (of about $0.5 \%$ ) in all $\alpha$-spectral peaks, except that for ${ }^{235} \mathrm{U}$. Two software programs were used for the spectrum analysis; viz., Maestro-32 (Ortec-Ametek Advanced Measurement 
Technology, Oak Ridge, TN, USA) and Genie 2000 (Canberra Industries, Inc., Meriden, CT, USA). Typical spectra for the unspiked and spiked sources are shown in Fig. 7. In all, eight spiked spectra were accumulated from the four independent replicate sources, with each source measured at two source-detector counting distances. These eight spectra were analyzed using the Genie program. Another collaborator independently analyzed four of the spectra from one counting position with the Maestro software.
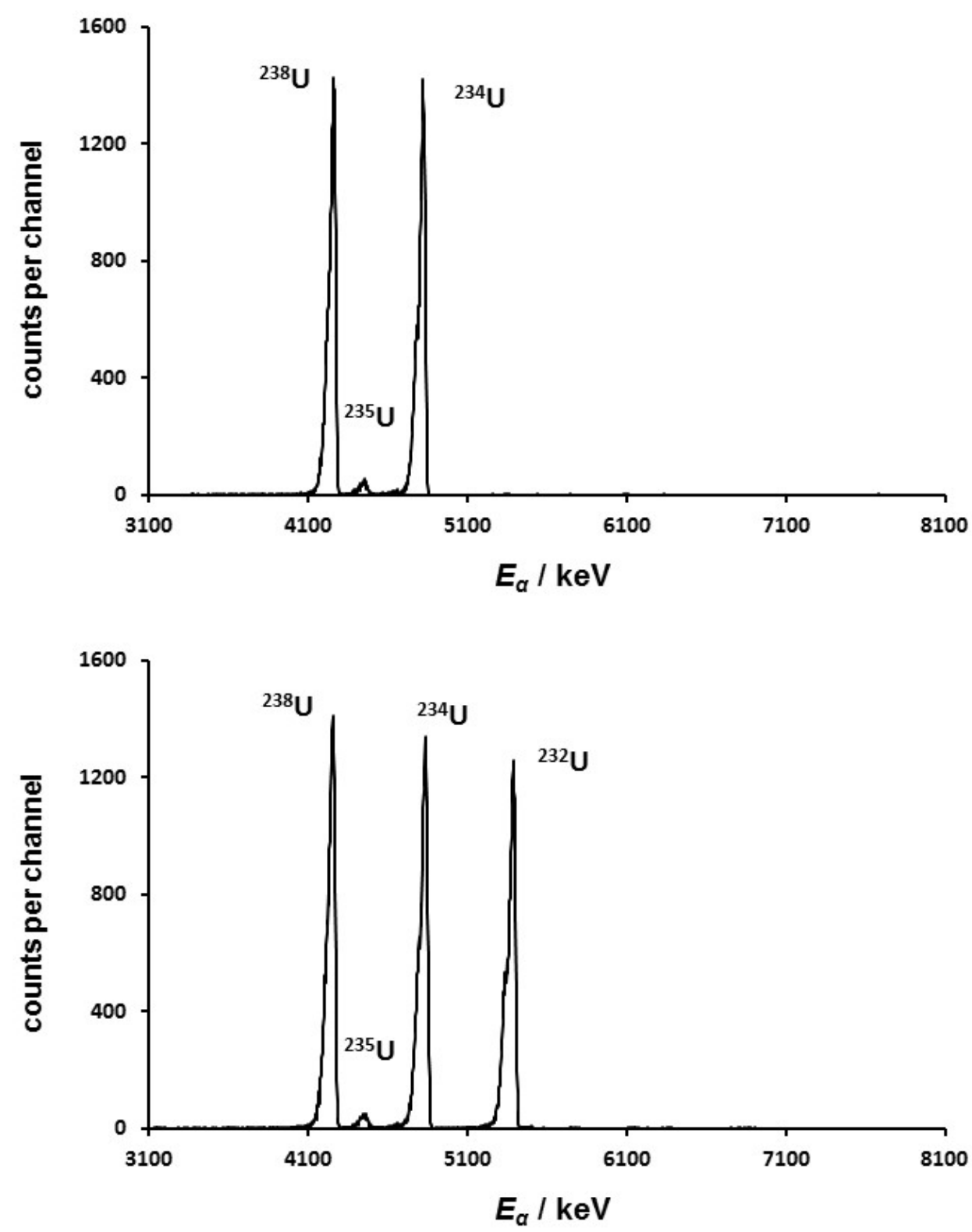

Fig. 7. Alpha-particle spectra from the isotope dilution analysis. Upper trace: typical spectrum for an unspiked natural uranium electrodeposited source, showing the peaks for ${ }^{238} \mathrm{U}$ and ${ }^{234} \mathrm{U}$, along with that for the weaker ${ }^{235} \mathrm{U}$. Lower trace: typical spectrum for a natural uranium electrodeposited source spiked with ${ }^{232} \mathrm{U}$ tracer (following chemical purification to remove the ${ }^{228} \mathrm{Th}$ daughter of ${ }^{232} \mathrm{U}$ ). Both spectra were accumulated for about $1.71 \mathrm{~d}$ with planar ion-implanted silicon detectors. No impurities were detected.

Figure 8 shows the collective results for the twelve determinations. The results are summarized in Table 8, along with a comparison with the certified massic activities for ${ }^{234} \mathrm{U}$ and ${ }^{238} \mathrm{U}$. Both the ${ }^{234} \mathrm{U}$ and 
${ }^{238} \mathrm{U}$ massic activity data sets (for $n=12$ ), along with the $A_{238 \mathrm{U}} / A_{234 \mathrm{U}}$ activity ratios were found to be normally distributed based on PPCC tests [15], with $p$ values of $0.31,0.76$, and 0.24 , respectively. These data sets also passed a Wilks-Shapiro test for normality, with $p$ values of $0.53,0.13$, and 0.85 , respectively. The relative difference in mean values for the two counting positions by the analyses using Genie was 0.03 $\%$ for ${ }^{234} \mathrm{U}$ and $0.17 \%$ for ${ }^{238} \mathrm{U}$. The relative difference between independent use of Genie and Maestro (and by different collaborators) in analyses of the same collected spectra was about $0.9 \%$ for both ${ }^{234} \mathrm{U}$ and ${ }^{238} \mathrm{U}$, corresponding to an estimated relative standard uncertainty of $0.25 \%$ uncertainty from the systematic difference in the two spectral analysis approaches. The main uncertainty components ( $>0.1 \%$ on relative basis) for the average massic activity of ${ }^{234} \mathrm{U}$ and ${ }^{238} \mathrm{U}$ were the measurement precision, Poisson counting statistics, massic activity for the ${ }^{232} \mathrm{U}$ tracer, and the correction for the ingrown ${ }^{228} \mathrm{Th}$ contribution into the ${ }^{232} \mathrm{U} \alpha$ peak. The uncertainty assessment is outlined in Table 9.

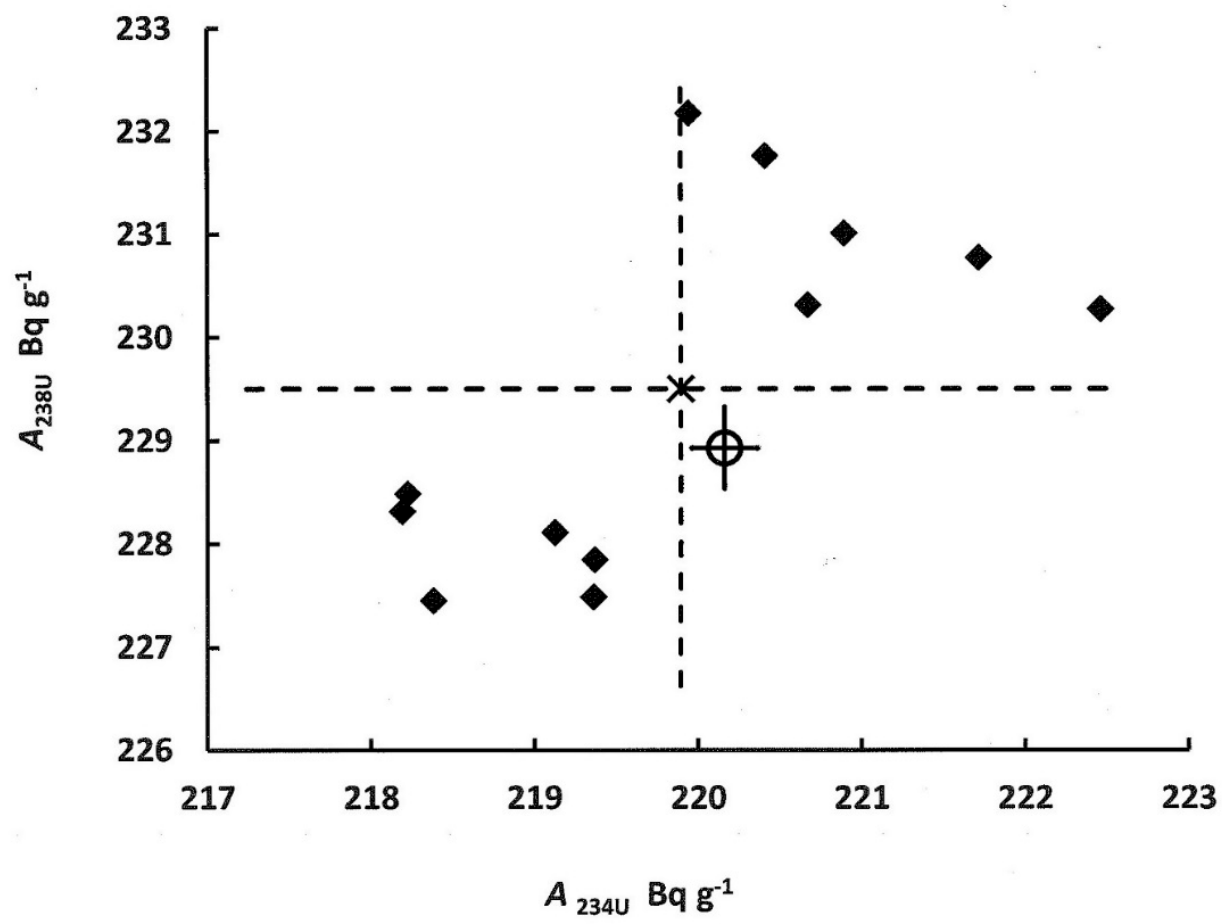

Fig. 8. Results showing the twelve determinations of the paired values for the massic activities of ${ }^{234} U$ and ${ }^{238} U$ as obtained from the isotope dilution $\alpha$ spectrometry. The cross represents the measured average values for $A_{234 \mathrm{U}}$ and $A_{238 \mathrm{U}}$. The lengths of the dashed horizontal and vertical lines correspond to expanded uncertainties $(k=2)$ on $A_{234 \mathrm{U}}$ and $A_{238 \mathrm{u}}$, respectively. The circle with solid horizontal and vertical bars represents the certified massic activities for $A_{234 \mathrm{U}}$ and $A_{238 \mathrm{U}}$ in SRM 4321d.

Table 8. Results of the isotope dilution analysis by $\alpha$-particle spectrometry using a ${ }^{232} \mathrm{U}$ tracer (SRM 4324B). The measurement values are based on twelve determinations of ${ }^{234} \mathrm{U}$ and ${ }^{238} \mathrm{U}$ obtained from four replicate counting sources in two geometries (eight spectra), where four spectra were independently analyzed by two independent spectral analysis procedures. The certified massic activities for SRM 4321d are taken from Table 2. Numbers in parentheses represent the numerical values of the expanded uncertainties (for $k=2$ ) and refer to the corresponding last digits of the quoted result. The uncertainty components that comprise the standard uncertainty for the measured values are given in Table 9 .

\begin{tabular}{|l|l|l|}
\hline \multirow{2}{*}{} & \multicolumn{2}{|l|}{ Massic activity $\left(\mathrm{Bq} \mathrm{g}^{-1}\right)$} \\
\cline { 2 - 3 } & $A_{234 \mathrm{U}}$ & $A_{238 \mathrm{U}}$ \\
\hline Measured value & $219.9(2.7)$ & $229.5(2.9)$ \\
\hline Certified value for SRM 4321d & $220.2(1.1)$ & $228.93(57)$ \\
\hline Relative difference & $-0.12 \%$ & $+0.25 \%$ \\
\hline
\end{tabular}


Table 9. Uncertainty assessment for the massic activities of ${ }^{234} U$ and ${ }^{238} U$ in standard SRM 4321d, as determined by isotope dilution analysis with $\alpha$-particle spectrometry, where $u$ (in percent) is the relative standard uncertainty for each component, as obtained from either a type A (evaluation by statistical methods) or type B (evaluation by other methods) assessment [6, 7].

\begin{tabular}{|c|c|c|c|c|}
\hline \multirow{2}{*}{\multicolumn{2}{|c|}{ Uncertainty component }} & \multirow{3}{*}{$\begin{array}{l}\text { Assessment type } \\
\text { A }\end{array}$} & \multicolumn{2}{|l|}{$u(\%)$} \\
\hline & & & \multirow{2}{*}{$\begin{array}{l}{ }^{234} \mathrm{U} \\
0.26\end{array}$} & \multirow{2}{*}{$\begin{array}{l}{ }^{238} \mathrm{U} \\
0.31\end{array}$} \\
\hline 1 & $\begin{array}{l}\text { Measurement precision; standard deviation of the mean for } n=12 \\
\text { determinations on four counting sources in two counting geometries (8 } \\
\text { spectra) }\end{array}$ & & & \\
\hline 2 & Massic activity of ${ }^{232} \mathrm{U}$ tracer from SRM 4324B Certificate [24] & $\mathrm{B}$ & 0.41 & 0.41 \\
\hline 3 & Poisson statistics “counting error”; partially embodied in component 1 & $\mathrm{~B}$ & 0.18 & 0.18 \\
\hline 4 & $\begin{array}{l}{ }^{228} \text { Th ingrowth correction in }{ }^{232} \mathrm{U} \text { peak analysis; varies in range } 0.1 \% \text { to } \\
0.3 \% \text { depending on measurement time }\end{array}$ & $\mathrm{B}$ & 0.2 & 0.2 \\
\hline 5 & Gravimetric mass measurements & $\mathrm{B}$ & 0.05 & 0.05 \\
\hline 6 & Spectral analysis for peak determinations & $\mathrm{B}$ & 0.25 & 0.25 \\
\hline 7 & Gravimetric dilution factor & $\mathrm{B}$ & 0.02 & 0.02 \\
\hline \multicolumn{3}{|c|}{ Relative combined standard uncertainty, $u_{c}$} & 0.61 & 0.63 \\
\hline \multicolumn{3}{|c|}{ Relative expanded uncertainty $(k=2), U$} & 1.22 & 1.26 \\
\hline
\end{tabular}

As seen in Fig. 8, the paired results for the measured massic activities for ${ }^{234} \mathrm{U}$ and ${ }^{238} \mathrm{U}$ are highly correlated. The correlation coefficient for $A_{238 \mathrm{U}}$ as a function of $A_{234 \mathrm{U}}$ is $r^{2}=0.45$, and the differences in both $A_{234 \mathrm{U}}$ and $A_{238 \mathrm{U}}$ from either of the measured mean values of certified values are either both positive (quadrant I of that shown) or both negative (quadrant III), meaning that the measured values for ${ }^{234} \mathrm{U}$ and ${ }^{238} \mathrm{U}$ scale in the same direction within the same spectrum.

No $\alpha$-emitting impurities were detected by way of the following evaluations. One aliquot of the SRM 4321d dilution (identified as source U5) that had not been spiked with ${ }^{232} \mathrm{U}$ was directly electrodeposited without any previous UTEVA extraction chromatography separation. Under the electrodeposition conditions, actinides $(Z=89$ to $Z=96)$ as well as $\mathrm{Bi}$ and Po were expected to be deposited with high yield on the stainless-steel disk. Radium would not deposit. In the resulting $147 \mathrm{ks} \alpha$ spectrum of source U5, no peaks (channels with more than 4 counts per channel) were observed in the regions $3.1 \mathrm{MeV}$ to $4.0 \mathrm{MeV}$ and $4.8 \mathrm{MeV}$ to $8.2 \mathrm{MeV}$ (i.e., those regions below and above the $4.1 \mathrm{MeV}$ to $4.7 \mathrm{MeV}$ range of the ${ }^{238} \mathrm{U}$, ${ }^{235} \mathrm{U}$, and ${ }^{234} \mathrm{U}$ peaks). The $3.1 \mathrm{MeV}$ to $4.0 \mathrm{MeV}$ region had counts that were attributable to "low-energy peak tailing” from the large ${ }^{238} \mathrm{U}$ peak. The $4.8 \mathrm{MeV}$ to $8.2 \mathrm{MeV}$ region had only scattered counts, the sum of which was not statistically different from that of background measurements in that region. The estimated lower limits of detection for $\alpha$-emitting impurities (excluding radium) relative to the ${ }^{238} \mathrm{U}$ signal in source U5 were $0.2 \%$ and $0.06 \%$ for regions $3.1 \mathrm{MeV}$ to $4.0 \mathrm{MeV}$ and $4.8 \mathrm{MeV}$ to $8.2 \mathrm{MeV}$, respectively. In addition, the ratio of the ${ }^{234} \mathrm{U}$ to ${ }^{238} \mathrm{U} \alpha$ peak counts in source U5 were compared to the corresponding ratio in the spiked samples. The difference of $0.5 \%$ was not significant when compared to the uncertainty from Poisson statistics "counting error" arising from the integral counts in the $\alpha$ peaks. This suggested that there were no interferences in the $4.2 \mathrm{MeV}$ and $4.7 \mathrm{MeV} \alpha$ lines of ${ }^{238} \mathrm{U}$ and ${ }^{234} \mathrm{U}$, respectively, that could be attributed to (1) isotopic or nonisotopic impurities that were present in the directly electrodeposited U5 source or (2) any isotopic impurities in the ${ }^{232} \mathrm{U}$ spike that were not removed by the UTEVA column.

\section{Certification of SRM 4321d and Summary}

The prepared natural uranium solution standards were certified for massic activities of ${ }^{234} \mathrm{U},{ }^{235} \mathrm{U}$, and

${ }^{238} \mathrm{U}$ on the basis of the isotopic atom percentages for metallic CRM 112-A, as obtained from mass spectrometry. The standards will be disseminated as NIST SRM 4321d with the following specifications [27]:

Radionuclides: $\quad$ Natural uranium (mixture of ${ }^{234} \mathrm{U},{ }^{235} \mathrm{U}$, and ${ }^{238} \mathrm{U}$ )

Reference time: $\quad 1200$ h EST, 15 March 2017

Massic activities of the solution: $\quad{ }^{234} \mathrm{U}: 220.16 \mathrm{~Bq} \mathrm{~g}^{-1}$; ${ }^{235} \mathrm{U}: 10.540 \mathrm{~Bq} \mathrm{~g}^{-1} ;{ }^{238} \mathrm{U}: 228.93 \mathrm{~Bq} \mathrm{~g}^{-1}$

Relative expanded uncertainties $(k=2):{ }^{234} \mathrm{U}: 0.52 \%$; ${ }^{235} \mathrm{U}: 0.31 \%$; ${ }^{238} \mathrm{U}: 0.25 \%$

The solution was also characterized in terms of the following uncertified information: 
Source description: Liquid in flame-sealed, $5 \mathrm{~mL}$ borosilicate glass ampoule Solution composition: $(1.06 \pm 0.06) \mathrm{mol} \mathrm{L}^{-1} \mathrm{HNO}_{3}$ with $21 \mathrm{mg} \mathrm{UO}_{2}{ }^{+2}$ per gram of solution

Solution density: $\quad(1.057 \pm 0.001) \mathrm{g} \mathrm{mL}^{-1}$ at $21.6^{\circ} \mathrm{C}$

Solution mass: $\quad(5.284 \pm 0.001) \mathrm{g}$

Radionuclidic impurities, including other uranium isotopes: none; ${ }^{233} \mathrm{U}$ and ${ }^{236} \mathrm{U}$ were not detected

Half-lives [4]:

${ }^{234} \mathrm{U}:(2.455 \pm 0.006) \times 10^{5} \mathrm{a}$

${ }^{235} \mathrm{U}:(7.04 \pm 0.01) \times 10^{8} \mathrm{a}$

${ }^{238} \mathrm{U}:(4.468 \pm 0.005) \times 10^{9} \mathrm{a}$

The uncertainty assessments for the certified massic activities are summarized in Table 3.

Confirmatory measurements by LS counting and by $\alpha$-spectrometry isotope dilution analysis verified the quantitative dissolution, dilution, and preparation of suitable $5 \mathrm{~mL}$ aliquots of the SRM. Experimental work also demonstrated SRM solution homogeneity and equivalence between SRM units, as well as consistency with the absence of radionuclidic impurities.

\section{Acknowledgments}

Dr. Ryan Fitzgerald (NIST Radioactivity Group) is thanked and deeply appreciated for his devil's advocacy during the experimental design, for critical commentary, and for independently checking the calculations for obtaining activity values from the isotopic mass data. Autoclave sterilization of the SRM ampoules by Dr. Willie Regits (NIST Research Associate) was appreciated. The authors would also like to acknowledge and thank Dr. Karsten Kossert (Physikalisch-Technische Bundesanstalt, Braunschweig, Germany) for providing the necessary atomic data input files for the MICELLE2 calculations. Dr. Lisa Karam, Radiation Physics Division Chief, and Dr. Michael Unterweger, Radioactivity Group Leader, are thanked for their enthusiastic support of this project.

Author contributions: R.C. oversaw and was principally responsible for the overall project. He also developed the experimental design and participated in every experimental aspect. All wet laboratory and gravimetric work, including the metal cleaning, dissolution, preparation of master solution, and production of the SRM ampoules, along with preparation of LS counting sources and dilutions, was performed by R.C. and L.L.P. The $\mathrm{NaI}(\mathrm{Tl})$ measurements and data reduction for the homogeneity evaluation were performed by R.C., with the assistance of D.E.B. for setting up the instrument and data retrieval. L.P. performed the HPGe photonic emission spectrometry for impurity analysis and the attempts at assaying the isotopic activities. The LS confirmatory measurements and data retrieval and reduction were made by L.L.P. The LS data analysis was done by R.C. and L.L.P. Calculations of the LS detection efficiencies for $\beta^{-}$-emitting ${ }^{231} \mathrm{Th},{ }^{234} \mathrm{Th}$, and ${ }^{234 \mathrm{~m}} \mathrm{~Pa}$ nuclides were performed by B.E.Z. Independent confirmatory measurements by $\alpha-$ particle isotope dilution analysis with $\alpha$-particle spectrometry were made by S.N. and J.J.L.R. R.C. performed all calculations for obtaining activity values from the isotopic mass data and the reconciliation with the confirmatory measurements. L.L.P. made checks and verifications of all final data analyses and calculations. All authors participated in initial discussions on the experimental design and procedures, particularly as it affected their respective contributions. R.C. wrote the first draft, and all authors participated in reviewing and editing the final version. L.L.P. was responsible for shepherding the manuscript through the submission and editorial process.

\section{References}

[1] Decay Data Evaluation Project (DDEP), recommended data accessible on-line. Available at http://www.nucleide.org/DDEP_WG/DDEPdata.htm. Accessed June 10, 2017.

[2] National Bureau of Standards (NBS) (November, 1986) NBS Certificate, Standard Reference Material 4321, Alpha-ParticleSolution Standard (NBS, Gaithersburg, MD) https://www-s.nist.gov/srmors/certificates/archives/4321.pdf; National Institute of Standards and Technology (NIST) (February, 1992) NIST Certificate, Standard Reference Material 4321B, Alpha-Particle Solution Standard (NIST, Gaithersburg, MD) https://www-s.nist.gov/srmors/certificates/archives/4321B.pdf; National Institute of Standards and Technology (NIST) (November 1997) NIST Certificate, Standard Reference Material 4321C, Natural Uranium Radioactivity Standard (NIST, Gaithersburg, MD) https://www-s.nist.gov/srmors/certificates/4321C.pdf. 
[3] Holen SR, Demeré TA, Fisher DC, Fullagar R, Paces JB, Jefferson GT, Beeton JM, Cerutti RA, Rountrey AN, Vescera L, Holen KA (2017) A 130,000-year-old archaeological site in southern California, USA. Nature 544:479-483, https://doi.org/10.1038/nature22065.

[4] Zimmer C (2017) Humans lived in North America 130,000 years ago, study claims. New York Times, April 26, 2017. Available at https//nyti.ms/2q616iB. Accessed May 5, 2017.

[5] New Brunswick Laboratory (NBL) (September 2010) NBL Certificate of Analysis, CRM 112-A, Uranium (Normal) Metal Assay and Isotopic Standard (NBL, U.S. Department of Energy, Argonne, IL). Available at https://science.energy.gov/ /media/nbl/pdf/price-lists/certificates/CRM_112A_Uranium_Metal_Sept_2010.pdf.

[6] Taylor BN, Kuyatt CE (1994) Guidelines for Evaluating and Expressing the Uncertainty of NIST Measurement Results. U.S. Department of Commerce, Washington, D.C., NIST Technical Note 1297. https://doi.org/10.6028/NIST.TN.1297.

[7] Joint Committee for Guides in Metrology (JCGM) (2008) Guide to the Expression of Uncertainty in Measurement (GUM). Pavillon de Breteuil, France, Joint Committee for Guides in Metrology (JCGM), JCGM 100:2008. Available at: https://www.bipm.org/en/publications/guides/gum.html.

[8] New Brunswick Laboratory (NBL) (2010) NBL Report NBL-RM-2010-CRM 112A (NBL, U.S. Department of Energy, Argonne, IL).

[9] National Bureau of Standards (NBS) (May 1972) NBS Certificate of Analysis, Standard Reference Material 960, Uranium Metal (NBS, Washington, D.C.).

[10] Katz JJ, Rabinowitch E, (1951) The Chemistry of Uranium (McGraw-Hill, NY).

[11] Gindler JE (1962) The Radiochemistry of Uranium (National Academy of Sciences, National Research Council, U.S. Atomic Energy Commission), Nuclear Science Series NAS-NS-3050.

[12] Cordfunke EHP (1969) The Chemistry of Uranium, Including its Applications in Nuclear Technology (Elsevier Publ. Co., Amsterdam, Netherlands).

[13] Larsen RP (1959) Dissolution of uranium metal and its alloys. Analytical Chemistry 31:545-549. https://doi.org/10.1021/ac50164a026.

[14] Lucas LL (NIST), personal communication (February 2017), and laboratory notebook records for SRM 4321c (July 1997).

[15] Filliben JJ (1972) The probability plot correlation test for normality. Technometrics 17(1):111-117. https://doi.org/10.1080/00401706.1975.10489279.

[16] Pibida L, Hsieh E, Fuentes-Figueroa A, Hammond MM, Karam L (2006) Software studies for germanium detector data analysis. Applied Radiation and Isotopes 64:1313-1318. https://doi.org/10.1016/j.apradiso.2006.02.076.

[17] Pibida L, Nafee SS, Unterweger M, Hammond MM, Karam L, Abbas MI (2006) Calibration of HPGe gamma-ray detectors for measurement of radioactive noble gas sources. Applied Radiation and Isotopes 65:225-233. https://doi.org/10.1016/j.apradiso.2006.07.002.

[18] Fitzgerald R, Forney AM (2011) Determination of the liquid scintillation counting inefficiency (wall effect) for alpha emitters, using the alpha-gamma anti-coincidence method. Radiocarbon, LSC 2010, Advances in Liquid Scintillation Spectrometry: Proceedings of the 2010 International Liquid Scintillation Conference, Paris, France, 6-10 September 2010, pp 331-339.

[19] Broda R, Cassette P, Kossert K (2007) Radionuclide metrology using liquid scintillation counting. Metrologia 44:S36-S52. https://doi.org/10.1088/0026-1394/44/4/S06.

[20] Grau Carles A, (2007) MICELLE2, the micelle size effect on LS counting efficiency. Computer Physics Communications 176:305-317. https://doi.org/10.1016/j.cpc.2006.11.002.

[21] Kossert K, Grau Carles A (2010) Improved method for the calculation of the counting efficiency of electron-capture nuclides in liquid scintillation counting. Applied Radiation and Isotopes 68:1482-1488. https://doi.org/10.1016/j.apradiso.2009.11.048.

[22] Kibédi T, Burrows TW, Trzhaskovskaya MB, Davidson PM, Nestor CW Jr (2008) Evaluation of theoretical conversion coefficients using BrICC. Nuclear Instruments and Methods in Physics Research A 589:202. https://doi.org/10.1016/j.nima.2008.02.051.

[23] National Institute of Standards and Technology (NIST) (February 2011) NIST Standard Reference Material 4926E, Hydrogen-3 Radioactivity Standard (NIST, Gaithersburg, MD). https://nemo.nist.gov/srmors/msds/4926E-MSDS.pdf.

[24] National Institute of Standards and Technology (NIST) (September 2004) NIST Standard Reference Material 4324B, Uranium232 Radioactivity Standard (NIST, Gaithersburg, MD). https://nemo.nist.gov/srmors/view_detail.cfm?srm=4324B.

[25] Rodriguez y Baena AM, Miquel J-C, Masqué P, Povinec PP, La Rosa J (2006) A single vs. double spike approach to improve the accuracy of ${ }^{234} \mathrm{Th}$ measurements in small-volume seawater samples. Marine Chemistry 100(3-4):269-281. https://doi.org/10.1016/j.marchem.2005.10.015.

[26] Inn KGW, Hall E, Woodward JT IV, Stewart B, Pollanen R, Selvig L, Turner S, Outola I, Nour S, Kurosaki H, La Rosa J, Schultz M, Lin Z, Yu Z, McMahon C (2008) Use of thin collodion films to prevent recoil-ion contamination of alphaspectrometry detectors. Journal of Radioanalytical and Nuclear Chemistry 276:385-390. https://doi.org/10.1007/s10967-0080516-y.

[27] National Institute of Standards and Technology (NIST) (June 2017) NIST Standard Reference Material 4321d, Natural Uranium Radioactivity Standard (NIST, Gaithersburg, MD). https://nemo.nist.gov/srmors/view_detail.cfm?srm=4321C.

About the authors: All authors are members of the Radioactivity Group in the Radiation Physics Division of the NIST Physical Measurement Laboratory. These seven collaborators collectively represent 132 years of experience in radionuclidic metrology at NIST. The National Institute of Standards and Technology is an agency of the U.S. Department of Commerce. 